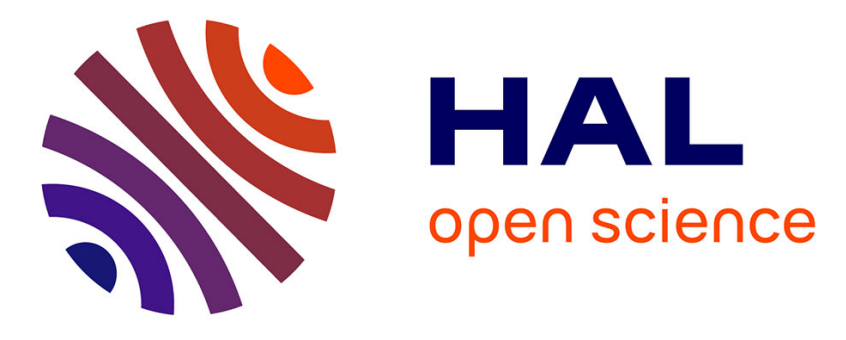

\title{
Copper Clusters Containing Hydrides in Trigonal Pyramidal Geometry
}

Rhone P Brocha Silalahi, Guan-Rong Huang, Jian-Hong Liao, Tzu-Hao Chiu, Kiran Kumarvarma Chakrahari, Xiaoping Wang, Julien Cartron, Samia Kahlal, Jean-Yves Saillard, C W Liu

\section{To cite this version:}

Rhone P Brocha Silalahi, Guan-Rong Huang, Jian-Hong Liao, Tzu-Hao Chiu, Kiran Kumarvarma Chakrahari, et al.. Copper Clusters Containing Hydrides in Trigonal Pyramidal Geometry. Inorganic Chemistry, 2020, 59 (4), pp.2536-2547. 10.1021/acs.inorgchem.9b03501 . hal-02472166

\section{HAL Id: hal-02472166 https://hal-univ-rennes1.archives-ouvertes.fr/hal-02472166}

Submitted on 26 Mar 2020

HAL is a multi-disciplinary open access archive for the deposit and dissemination of scientific research documents, whether they are published or not. The documents may come from teaching and research institutions in France or abroad, or from public or private research centers.
L'archive ouverte pluridisciplinaire HAL, est destinée au dépôt et à la diffusion de documents scientifiques de niveau recherche, publiés ou non, émanant des établissements d'enseignement et de recherche français ou étrangers, des laboratoires publics ou privés. 


\section{Copper Clusters Containing Hydrides in Trigonal}

\section{Pyramidal Geometry}

Rhone P. B. Silalahi, ${ }^{\dagger}$ Guan-Rong Huang, ${ }^{\dagger}$ Jian-Hong Liao, ${ }^{\dagger}$ Tzu-Hao Chiu ${ }^{\dagger}$ Kiran

Kumarvarma Chakrahari, ${ }^{\dagger}$ Xiaoping Wang, ${ }^{\S}$ Julien Cartron, ${ }^{\ddagger}$ Samia Kahlal, ${ }^{\ddagger}$ Jean-Yves

Saillard, ${ }^{*}$ and C. W. Liu ${ }^{*^{\dagger}}$

${ }^{\dagger}$ Department of Chemistry, National Dong Hwa University No. 1, Sec. 2, Da Hsueh Rd.

Shoufeng, Hualien 97401 (Taiwan R. O. C.)

${ }^{\S}$ Neutron Scattering Division, Neutron Sciences Directorate Oak Ridge National Laboratory, Oak

Ridge, TN 37831 (USA)

${ }^{\ddagger}$ Univ Rennes, CNRS, ISCR-UMR 6226, F-35000 Rennes, France

KEYWORDS: Copper, hydride, pentacapped trigonal prism, S-donor ligands

ABSTRACT: Structurally precise copper hydrides $\left[\mathrm{Cu}_{11} \mathrm{H}_{2}\left\{\mathrm{~S}_{2} \mathrm{P}\left(\mathrm{O}^{i} \mathrm{Pr}\right)_{2}\right\}_{6}(\mathrm{C} \equiv \mathrm{CR})_{3}\right]$, $(\mathrm{R}=\mathrm{Ph}(\mathbf{1})$, $\mathrm{C}_{6} \mathrm{H}_{4} \mathrm{~F}$ (2) and $\mathrm{C}_{6} \mathrm{H}_{4} \mathrm{OMe}$ (3) were first synthesized from the polyhydrido copper cluster $\left[\mathrm{Cu}_{20} \mathrm{H}_{11}\left\{\mathrm{~S}_{2} \mathrm{P}\left(\mathrm{O}^{i} \mathrm{Pr}\right)_{2}\right\}_{9}\right]$ with nine equiv. of terminal alkynes. Later their isolated yields were significantly improved by direct synthesis from $\left[\mathrm{Cu}\left(\mathrm{CH}_{3} \mathrm{CN}\right)_{4}\right]\left(\mathrm{PF}_{6}\right),\left[\mathrm{NH}_{4}\right]\left[\mathrm{S}_{2} \mathrm{P}\left(\mathrm{O}^{i} \mathrm{Pr}\right)_{2}\right], \mathrm{NaBH}_{4}$, and alkynes along with $\mathrm{NEt}_{3}$ in THF. 1, 2, and $\mathbf{3}$ were fully characterized by single-crystal X-ray diffraction, ESI-MS and multinuclear NMR spectroscopy. All three clusters have eleven copper atoms adopting 3, 3, 4, 4, 4-pentaccaped trigonal prismatic geometry, with two hydrides inside the $\mathrm{Cu}_{11}$ cage, the position of which being ascertained by a single-crystal neutron diffraction structure of cluster 1 co-crystallized with a $\left[\mathrm{Cu}_{7}(\mathrm{H})\left\{\mathrm{S}_{2} \mathrm{P}\left(\mathrm{O}^{i} \mathrm{Pr}\right)_{2}\right\}_{6}\right], 4$ cluster. Six dithiophosphate and three alkynyl ligands stabilize the $\mathrm{Cu}_{11} \mathrm{H}_{2}$ core in which the two hydrides adopt a trigonal pyramidal coordination mode. This coordination mode is so far unprecedented for hydride. The ${ }^{1} \mathrm{H}$ NMR resonance frequency of the two hydrides appears at $4.8 \mathrm{ppm}$, a value further confirmed 
by ${ }^{2} \mathrm{H}$ NMR spectroscopy for their deuteride derivatives $\left[\mathrm{Cu}_{11}(\mathrm{D})_{2}\left\{\mathrm{~S}_{2} \mathrm{P}\left(\mathrm{O}^{i} \mathrm{Pr}\right)_{2}\right\}_{6}(\mathrm{C} \equiv \mathrm{CR})_{3}\right]$. A DFT investigation allows understanding the bonding within this new type of copper(I) hydrides.

\section{INTRODUCTION}

Stereochemistry and properties are strongly related. This is why the exceedingly popular X-ray crystallography technique is the method of choice for understanding molecular properties. However, in the case of hydride-containing complexes and clusters, X-ray diffraction fails to assess the bonding features of the hydride ions, thus not allowing comprehending the properties associated with. This is why rarely has literature addressed the surroundings of hydrides unless neutron diffraction data are available. ${ }^{1}$ Under this guideline, our group has managed to uncover new coordination geometry of hydrides from several copper hydrides despite the difficulty in growing good quality single crystals for neutron diffraction. ${ }^{\text {b-f }}$ Among these, five-coordinated hydrides $\left(\mu_{5}-\mathrm{H}\right)$ in both square pyramidal and trigonal bipyramidal, ${ }^{1 b}$ and four-coordinated hydrides $\left(\mu_{4}-\mathrm{H}\right)$ in tetrahedral and square planar $^{1 \mathrm{f}}$ can be thoroughly discussed. In these compounds, the hypercoordinated hydrides, which are surrounded by a certain number of metal atoms, can be viewed as inverse coordinated centers, within the concept of inversed coordination defined recently by Haiduc, ${ }^{2}$ that is the formation of metal compounds in which the acceptor and donor sites are reversed compared to conventional coordination complexes.

Encapsulation of main group anions in transition metal frameworks remains an active field in cluster science and provides solid examples of inversed coordination. Owing to their variable coordination modes, halides and chalcogenides are the most studied species and have yielded planar, tetrahedral, octahedral, and cubic coordination patterns. ${ }^{2}$ The latter is frequently observed in dithiophosph(in)ate-stabilized $\mathrm{M}_{8}^{\mathrm{I}}(\mathrm{M}=\mathrm{Cu}, \mathrm{Ag})$ cubic clusters encapsulating $\mathrm{S}^{2-}, \mathrm{Cl}^{-}$ , and $\mathrm{Br}^{-}{ }^{3}$ Our research group has reported selenide- and halide-centered cubes, $\mathrm{Cu}_{8}\left(\mu_{8^{-}}\right.$ $\left.\mathrm{Se})\left\{\mathrm{Se}_{2} \mathrm{P}\left(\mathrm{O}^{i} \mathrm{Pr}\right)_{2}\right\}_{6}\right],{ }^{4}\left[\mathrm{Ag}_{8}\left(\mu_{8^{-}} \mathrm{Se}\right)\left\{\mathrm{Se}_{2} \mathrm{P}\left(\mathrm{O}^{i} \mathrm{Pr}\right)_{2}\right\}_{6}\right],{ }^{5}\left[\mathrm{Cu}_{8}\left(\mu_{8}-\mathrm{X}\right)\left\{\mathrm{Se}_{2} \mathrm{P}(\mathrm{OR})_{2}\right\}_{6}\right]\left(\mathrm{PF}_{6}\right),{ }^{6}$ and $\left[\mathrm{Ag}_{8}\left(\mu_{8^{-}}\right.\right.$ $\left.\mathrm{X})\left\{\mathrm{Se}_{2} \mathrm{P}(\mathrm{OR})_{2}\right\}_{6}\right]\left(\mathrm{PF}_{6}\right)(\mathrm{X}=\mathrm{F}, \mathrm{Cl}, \mathrm{Br})^{7}$

The configuration of eleven metal atoms in a pentacapped trigonal prismatic arrangement appears to be prototypical for silver(I) and copper(I) surrounded by both halides and dichalcogenolates. Notable examples are $\left[\mathrm{Cu}_{11}\left(\mu_{9}-\mathrm{Se}\right)\left(\mu_{3}-\mathrm{X}\right)_{3}\left\{\mathrm{Se} e_{2} \mathrm{P}(\mathrm{OR})_{2}\right\}_{6}\right]\left(\mathrm{R}=\mathrm{Et}, \mathrm{Pr},{ }^{\mathrm{i}} \mathrm{Pr}\right.$; $\mathrm{X}=\mathrm{Br}, \mathrm{I}){ }^{8}\left[\mathrm{Ag}_{11}\left(\mu_{9}-\mathrm{Se}\right)\left(\mu_{3}-\mathrm{X}\right)_{3}\left\{\mathrm{Se}_{2} \mathrm{P}(\mathrm{OR})_{2}\right\}_{6}\right]\left(\mathrm{R}=\mathrm{Et}, \mathrm{Pr},{ }^{\mathrm{i}} \mathrm{Bu} ; \mathrm{X}=\mathrm{Br}, \mathrm{I}\right)^{9}$ and $\left[\mathrm{Ag}_{11}\left(\mu_{9^{-}} \mathrm{I}\right)\left(\mu_{3^{-}}\right.\right.$ 
$\left.\mathrm{I})_{3}\left\{\mathrm{E}_{2} \mathrm{P}\left(\mathrm{O}^{\mathrm{i}} \mathrm{Pr}\right)_{2}\right\}_{6}\right] \quad(\mathrm{E}=\mathrm{S}$, Se $){ }^{10}\left[\mathrm{Cu}_{11}\left(\mu_{9}-\mathrm{X}\right)\left(\mu_{3}-\mathrm{X}\right)_{3}\left\{\mathrm{~S}_{2} \mathrm{P}\left(\mathrm{O}^{i} \mathrm{Pr}\right)_{2}\right\}_{6}\right]^{+}\left(\mathrm{X}=\mathrm{Br}\right.$, I), and $\left[\mathrm{Cu}_{11}\left(\mu_{9^{-}}\right.\right.$ $\left.\mathrm{S})\left(\mu_{3}-\mathrm{X}\right)_{3}\left\{\mathrm{~S}_{2} \mathrm{P}\left(\mathrm{O}^{i} \mathrm{Pr}\right)_{2}\right\}_{6}\right](\mathrm{X}=\mathrm{Br}, \mathrm{I}){ }^{11}$ which all house a nanocoordinated sulfide, selenide, or halide at the center of tricapped trigonal-prism (Scheme 1). Cluster stability of this type studied by Density Functional Theory (DFT) has been attributed to the ionocovalent interactions between the central closed-shell anion and the host copper (or silver) atoms, besides the strong M-E (or M-X) covalent bonding. On the other side, encapsulation of two closed-shell anions inside single $\mathrm{M}_{11}$ cage is not known, to the best of our knowledge.

Herein we report three heteroleptic $\mathrm{Cu}_{11}$ cages, $\left[\mathrm{Cu}_{11} \mathrm{H}_{2}\left\{\mathrm{~S}_{2} \mathrm{P}\left(\mathrm{O}^{i} \mathrm{Pr}\right)_{2}\right\}_{6}(\mathrm{C} \equiv \mathrm{CR})_{3}\right]$, which contain two encapsulated hydrides. They are produced from the degradation of a polyhydrido copper cluster, $\left[\mathrm{Cu}_{20} \mathrm{H}_{11}\left\{\mathrm{~S}_{2} \mathrm{P}\left(\mathrm{O}^{i} \mathrm{Pr}\right)_{2}\right\}_{9}\right]$, ${ }^{1 \mathrm{e}}$ with nine equiv. of terminal alkynes. Interestingly, this is the first proof of two hydrides located within a pentaccapped trigonal prismatic cage of eleven $\mathrm{Cu}(\mathrm{I})$ atoms. Unexpectedly, the two hydrides were found to be four-coordinated and exhibiting a brand-new trigonal pyramidal geometry, never observed so far in metal hydride chemistry.

A
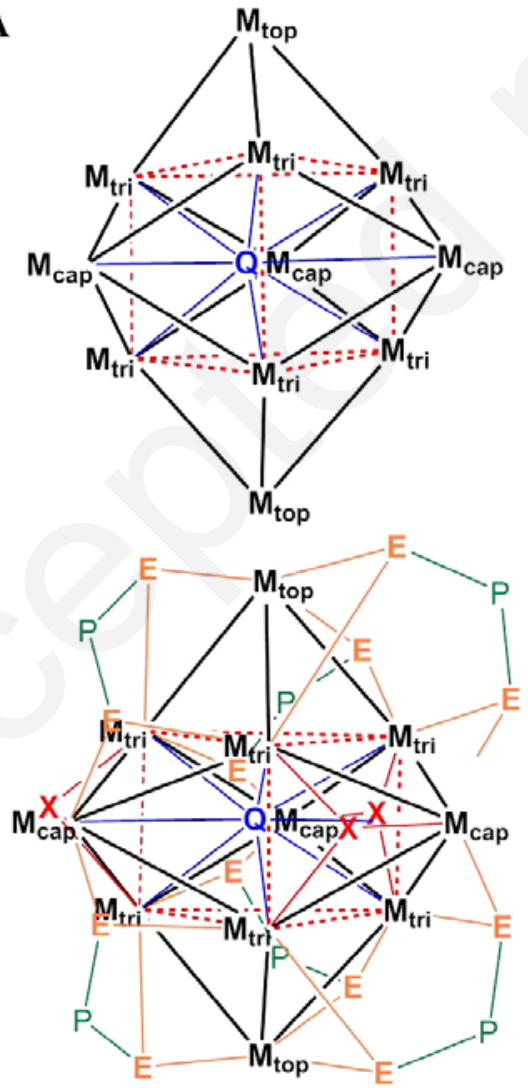

B
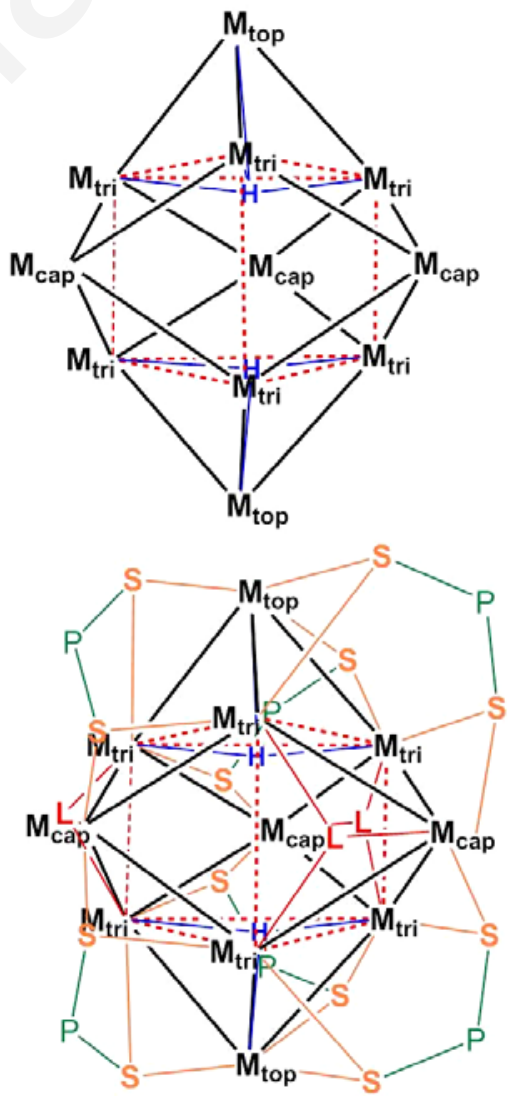

$\mathrm{M}=\mathrm{Cu} / \mathrm{Ag} ; \mathrm{E}=\mathrm{S} / \mathrm{Se} ; \mathrm{Q}=\mathrm{S} / \mathrm{Se} / \mathrm{Br} / \mathrm{I} ; \mathrm{X}=\mathrm{Br} / \mathrm{I} ; \mathrm{L}=\mathrm{C} \equiv \mathrm{CR}$ 
Scheme 1. Sketches of (A) the anion-centered pentacapped trigonal prismatic metal cages stabilized by three halides and six dichalcogenolates; (B) the pentacapped trigonal prismatic copper(I) cage with two interstitial hydrides. The alkoxy groups and phenyl rings are omitted for clarity.

\section{RESULTS AND DISCUSSION}

Nine equiv. of terminal alkynes were added to a THF suspension of $\left[\mathrm{Cu}_{20} \mathrm{H}_{11}\left\{\mathrm{~S}_{2} \mathrm{P}\left(\mathrm{O}^{i} \mathrm{Pr}\right)_{2}\right\}_{9}\right] .{ }^{1 \mathrm{e}}$ The reaction was stirred at $30^{\circ} \mathrm{C}$ for $48 \mathrm{~h}$ and the color of suspension changed from dark orange into dark brown. Workup of this reaction resulted in the isolation of new clusters $\left[\mathrm{Cu}_{11}(\mathrm{H})_{2}\left\{\mathrm{~S}_{2} \mathrm{P}\left(\mathrm{O}^{i} \mathrm{Pr}\right)_{2}\right\}_{6}(\mathrm{C} \equiv \mathrm{CR})_{3}\right]$, where $\mathrm{R}=\mathrm{Ph}(\mathbf{1}), \mathrm{C}_{6} \mathrm{H}_{4} \mathrm{~F}$ (2) and $\mathrm{C}_{6} \mathrm{H}_{4} \mathrm{OMe}$ (3) as yellow precipitates in $10 \%, 9.6 \%$ and $20.4 \%$ yield. The by-products $\left[\mathrm{Cu}_{7}(\mathrm{H})\left\{\mathrm{S}_{2} \mathrm{P}\left(\mathrm{O}^{i} \mathrm{Pr}\right)_{2}\right\}_{6}\right]$ (4) was also formed during the reaction. The yields of 1 and 2 can be increased to $48.7 \%$ and $47.4 \%$, respectively, by direct reaction of $\left[\mathrm{Cu}\left(\mathrm{CH}_{3} \mathrm{CN}\right)_{4}\right]\left(\mathrm{PF}_{6}\right),\left[\mathrm{NH}_{4}\right]\left[\mathrm{S}_{2} \mathrm{P}\left(\mathrm{O}^{i} \mathrm{Pr}\right)_{2}\right],\left[\mathrm{BH}_{4}\right]^{-}$and alkynes along with $\mathrm{NEt}_{3}$, where the mole ratios are 3.5:2:1:4:4 at $30^{\circ} \mathrm{C}$ under $\mathrm{N}_{2}$ condition (Scheme 2). Their deuteride derivatives $\left[\mathrm{Cu}_{11}(\mathrm{D})_{2}\left\{\mathrm{~S}_{2} \mathrm{P}\left(\mathrm{O}^{i} \mathrm{Pr}\right)_{2}\right\}_{6}(\mathrm{C} \equiv \mathrm{CR})_{3}\right]$, where $\mathrm{R}=\mathrm{Ph}\left(\mathbf{1}_{\mathbf{D}}-50.7 \%\right), \mathrm{C}_{6} \mathrm{H}_{4} \mathrm{~F}$ $(2 \mathbf{D}-55.3 \%)$ and $\mathrm{C}_{6} \mathrm{H}_{4} \mathrm{OMe}\left(\mathbf{3}_{\mathbf{D}}-19.7 \%\right)$ were synthesized to support the existence of hydrides in the cluster.

$$
\begin{aligned}
{\left[\mathrm{Cu}_{20}\left(\mathrm{H}_{111}\left\{\mathrm{~S}_{2} \mathrm{P}\left(\mathrm{O}^{i} \mathrm{Pr}\right)_{2}\right\} 9\right]+9 \mathrm{HC} \equiv\right.} & \mathrm{CR} \underset{48 \mathrm{~h}, 30^{\circ} \mathrm{C}}{\stackrel{\mathrm{THF}}{\longrightarrow}}\left[\mathrm{Cu}_{11}\left(\mathrm{H}_{2}\left\{\mathrm{~S}_{2} \mathrm{P}\left(\mathrm{O}^{i} \mathrm{Pr}\right)_{2}\right\}_{6}(\mathrm{C} \equiv \mathrm{CR})_{3}\right]\right. \\
& -\left[\mathrm{Cu}_{7} \mathrm{H}\left\{\mathrm{S}_{2} \mathrm{P}\left(\mathrm{O}^{i} \mathrm{Pr}\right)_{2}\right\}_{6}\right]
\end{aligned}
$$

$$
\begin{gathered}
11\left[\mathrm{Cu}_{(}\left(\mathrm{CH}_{3} \mathrm{CN}\right)_{4}\right](\mathrm{PF} 6)+{ }_{6\left[\mathrm{NH}_{4}\right]\left[\mathrm{S}_{2} \mathrm{P}(\mathrm{OiPr})_{2}\right]}+3 \mathrm{HC} \equiv \mathrm{CR}+2 \mathrm{NaBH}_{4} \underset{3 \mathrm{~h}, 30^{\circ} \mathrm{C}}{\stackrel{\mathrm{THF}, \mathrm{NEt}_{3}}{\longrightarrow}}\left[\mathrm{Cu}_{11}\left(\mathrm{H}_{2}\left\{\mathrm{~S}_{2} \mathrm{P}\left(\mathrm{O}^{i} \mathrm{Pr}\right)_{2}\right\}_{6}(\mathrm{C} \equiv \mathrm{CR})_{3}\right]\right. \\
-\left[\mathrm{Cu} 7 \mathrm{H}\left\{\mathrm{S}_{2} \mathrm{P}\left(\mathrm{O}^{i} \mathrm{Pr}_{2}\right\}_{6}\right]\right.
\end{gathered}
$$

Scheme 2. General synthesis of 1,2 and 3. 
The chemical compositions of $\mathbf{1}, \mathbf{2}$, and $\mathbf{3}$ were firstly assessed by electrospray ionization

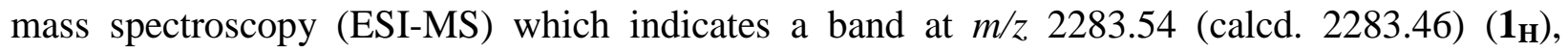

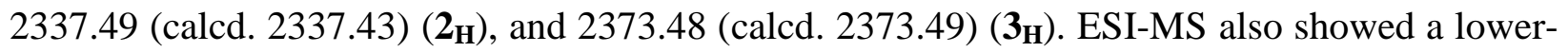
intensity mass peak attributed to the adduct-ion peak of $\left[\mathrm{Cu}_{11} \mathrm{H}_{2}\left\{\mathrm{~S}_{2} \mathrm{P}\left(\mathrm{O}^{i} \mathrm{Pr}\right)_{2}\right\}_{6}(\mathrm{C} \equiv \mathrm{CR})_{3}+\mathrm{Cu}^{+}\right]^{+}$, at $\mathrm{m} / \mathrm{z} 2346.48$ (calcd. 2346.38), 2400.43 (calcd. 2400.36), and 2436.41 (calcd. 2436.42). In addition an adduct ion peak corresponding to $\left[\mathrm{Cu}_{7}(\mathrm{H})\left\{\mathrm{S}_{2} \mathrm{P}\left(\mathrm{O}^{i} \mathrm{Pr}\right)_{2}\right\}_{6}+\mathrm{Cu}^{+}\right]^{+}$was also found (Figure S23). The spectra of the deuteride derivatives of 1, $\mathbf{2}$ and $\mathbf{3}$ depict an identical pattern with peaks at m/z 2285.45 (calcd. 2283.46) (1 $\mathbf{D}$ ), 2338.52 (calcd. 2337.43) (2 ) and 2375.48 (calcd. 2373.49) (3 $\left.\mathbf{3}_{\mathbf{D}}\right)$. The adduct ions $\left[\mathbf{X}+\mathrm{Cu}^{+}\right]^{+}(\mathbf{X}=\mathbf{1}, \mathbf{2}$ and 3) were also assigned to prominent peaks observed respectively at $\mathrm{m} / \mathrm{z} 2348.37$ (calcd 2346.48), 2402.53 (calcd. 2400.36) and 2438.42 (calcd. 2436.42). The simulated isotopic patterns of $[\mathbf{X}]$ and $\left[\mathbf{X}+\mathrm{Cu}^{+}\right]^{+}(\mathbf{X}=\mathbf{1}, \mathbf{2}$ and 3) are in good agreement with the experimental ones as shown in Figures 1 and S17-S22. The peaks of $\left[\mathbf{X}_{\mathbf{H}}\right]$ and $\left[\mathbf{X}_{\mathbf{H}}+\mathrm{Cu}^{+}\right]^{+}$are 1.99 mass unit lower than that of $\left[\mathbf{X}_{\mathbf{D}}\right]$ and $\left[\mathbf{X}_{\mathbf{D}}+\mathrm{Cu}^{+}\right]^{+}$, respectively, manifesting the presence of two hydrides in the neutral cluster.

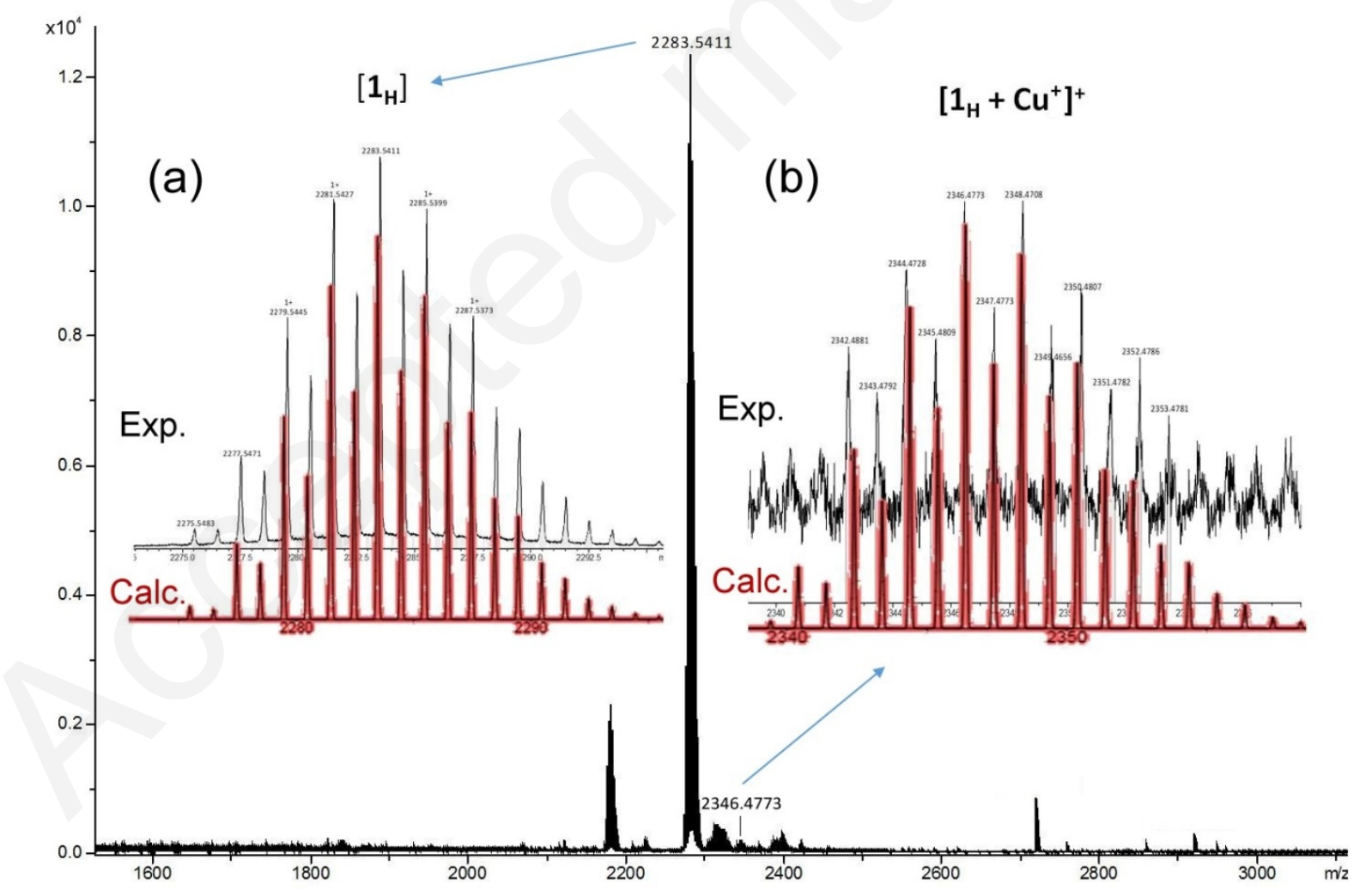

Figure 1. ESI-MS of $\left[\mathbf{1}_{\mathbf{H}}\right]$ and $\left[\mathbf{1}_{\mathbf{H}}+\mathrm{Cu}^{+}\right]^{+}$. Inset show experimental and simulated mass spectra of (a) $\left[\mathbf{1}_{\mathrm{H}}\right]$ and (b) $\left[\mathbf{1}_{\mathrm{H}}+\mathrm{Cu}^{+}\right]^{+}$. 
${ }^{1} \mathrm{H}$ NMR spectroscopy of clusters $\mathbf{1}, \mathbf{2}$, and $\mathbf{3}$ displays two sets of proton resonances corresponding to the alkyl group of the dithiophosphate (dtp) ligands and one set of chemical shifts assignable to the alkynyl ligands. However only one ${ }^{31} \mathrm{P}$ chemical shift at 103.9, 103.6 and $104.0 \mathrm{ppm}$, respectively, is observed for clusters $1 \sim 3$ (Figure S6-S11). The observed ${ }^{1} \mathrm{H}$ NMR chemical shift patterns strongly suggest that there is no two-fold symmetry imposed on the dtp ligand. The two hydrides in $\mathbf{1}_{\mathbf{H}}$ display a single peak at $4.75 \mathrm{ppm}$ in $\mathrm{CDCl}_{3}$ (Figure 2a). That of its deuteride analog, $\mathbf{1}_{\mathbf{D}}$, appears at $4.82 \mathrm{ppm}$ in chloroform at $297 \mathrm{~K}$ (Figure 2b). Comparable values are observed for $\mathbf{2}_{\mathbf{H}}$ and $\mathbf{2}_{\mathbf{D}}$ (4.75 and $4.82 \mathrm{ppm}$, see Figures $\mathrm{S} 1$ and $\mathrm{S} 12$ ) and for $\mathbf{3}_{\mathbf{H}}$ and 3D (4.65 and $4.70 \mathrm{ppm}$, see Figures S2 and S13) in $\mathrm{CDCl}_{3}$ and $\mathrm{CHCl}_{3}$ respectively. The accurate integration ratio of ${ }^{1} \mathrm{H}$ NMR resonances of clusters 1-3 fully confirms their overall compositions, that is: two hydrides, six dithiophosphates and three alkynyl ligands. The FT-IR spectra of the hydride and deuteride derivatives of 1-3 show great similarities. The $v(\mathrm{C} \equiv C)$ stretching vibrations of the coordinated alkynyl ligands at $2009.9\left(\mathbf{1}_{\mathbf{H}}\right), 2001.6\left(\mathbf{2}_{\mathbf{H}}\right), 2000.9\left(\mathbf{3}_{\mathbf{H}}\right)$ and 2010.6 (1) 2000.4 (2 $\mathbf{D}), 2001.1$ (3D) $\mathrm{Cm}^{-1}$ (Figure S24-S29) are found at lower frequencies than those of the free alkynes $\left(v\left(\mathrm{HC} \equiv \mathrm{CC}_{6} \mathrm{H}_{5}\right)\right)=2110 \mathrm{~cm}^{-1}, \quad(v(\mathrm{HC} \equiv \mathrm{C} 6 \mathrm{H} 4 \mathrm{~F}))=2115 \mathrm{~cm}^{-1}$ and $\left(v\left(\mathrm{HC} \equiv \mathrm{CC}_{6} \mathrm{H}_{4} \mathrm{OCH}_{3}\right)\right)=2107 \mathrm{~cm}^{-1}$. These values are slightly lower than that in $\left[\mathrm{Cu}_{13}\left\{\mathrm{~S}_{2} \mathrm{CN}^{n} \mathrm{Bu}_{2}\right\}_{6}\left(\mathrm{C}_{2} \mathrm{Ph}\right)_{4}\right]^{+}\left(2019 \mathrm{~cm}^{-1}\right){ }^{12}$ 


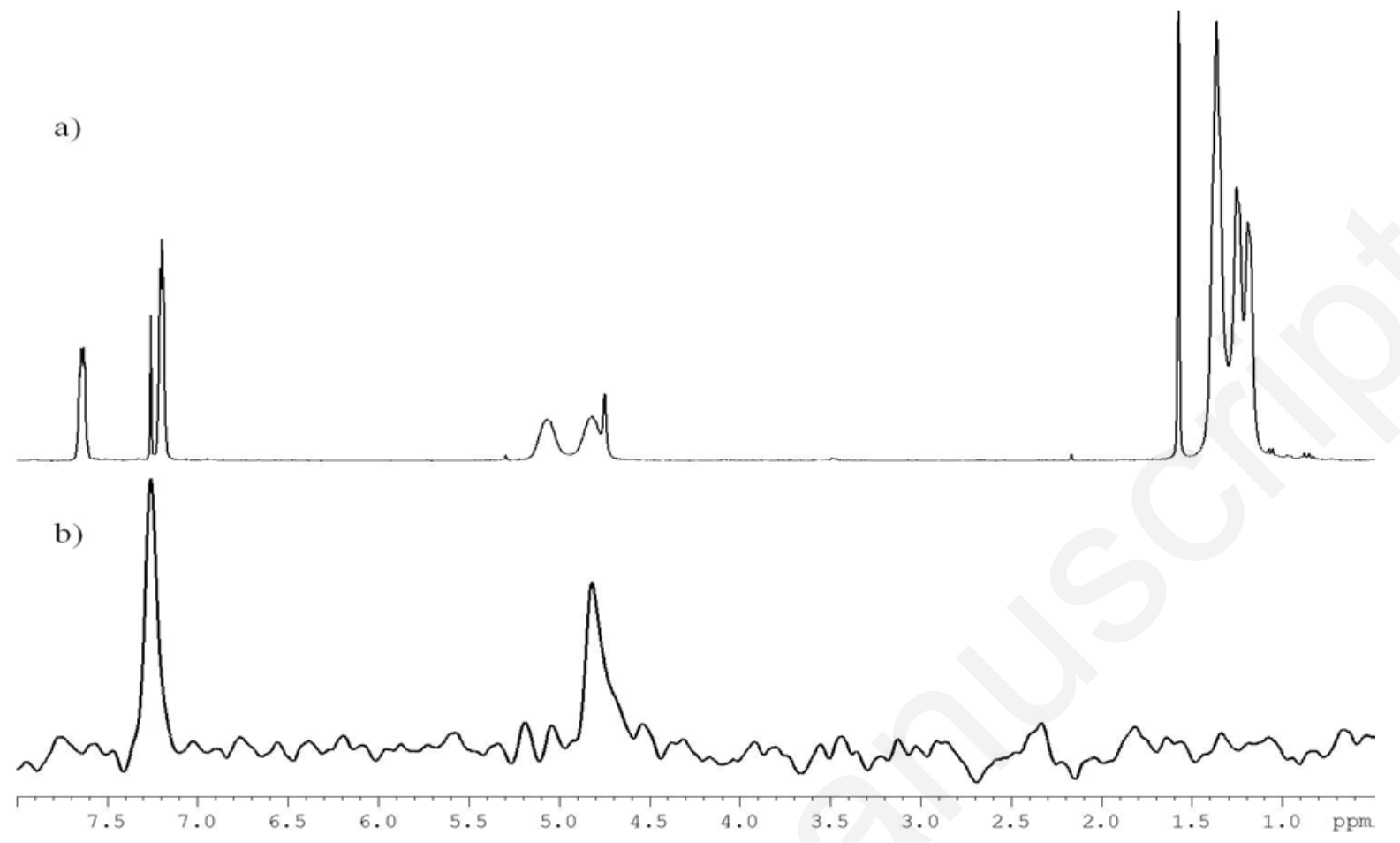

Figure 2. a) ${ }^{1} \mathrm{H}$ NMR spectrum of compound $\mathbf{1}_{\mathbf{H}}$ in $\mathrm{CDCl}_{3}$ and b) ${ }^{2} \mathrm{H}$ spectrum of compound $\mathbf{1}_{\mathbf{D}}$ in $\mathrm{CHCl}_{3}$.

Selected metric data from the molecular structures of clusters 1-3, determined by single X-ray and neutron diffraction (vide infra) analyses, are given in Table 1 . Views of these molecular structures can be seen in Figure 3 and Figures S31-S33. Their general features are similar and analogous to $\left[\mathrm{Cu}_{11}\left(\mu_{9}-\mathrm{Se}\right)(\mathrm{Br})_{3}\left\{\mathrm{~S}_{2} \mathrm{P}\left(\mathrm{O}^{i} \mathrm{Pr}\right)_{2}\right\}_{6}\right]$ and $\left[\mathrm{Ag}_{11}\left(\mu_{9}-\mathrm{I}\right)\left(\mu_{3}-\mathrm{I}\right)_{3}\left\{\mathrm{E}_{2} \mathrm{P}\left(\mathrm{O}^{i} \mathrm{Pr}\right)_{2}\right\}_{6}\right]$ $[\mathrm{E}=\mathrm{Se}, \mathrm{S}] .{ }^{8-11}$ The whole copper cage adopts the geometry a 3, 3, 4, 4, 4-pentaccaped trigonal prism, i.e., the $\mathrm{Cu}_{6}$ triangular prism of which the three rectangular and the two triangular faces are capped by an additional copper atom (Figures 3a-3b and S30). The highest ideal symmetry possible for such a $\mathrm{Cu}_{11}$ cage is thus $D_{3 h}$. This metal framework is stabilized by three alkynyls and six dtp ligands (Figure 3c). Half of the dtp alkyl groups are oriented towards the alkynes, i.e., along the sides of the metal framework, whereas the remaining half are oriented away from the metal core (Figure 3d). This is in full agreement with the NMR results mentioned above. The six dtp ligands, each bridging four copper atoms in a $\mu_{2}, \mu_{2}$ binding mode, are equally distributed on the right and left sides of the cluster along the horizontal $\mathrm{C}_{3}$ axis. The three alkynyl ligands are arranged along the waist of the pentacapped prism, alternatively binding to top and bottom 
triangles in $\mu_{3}-\eta^{1}$ fashion. As a result of ligand capping configuration, the ideal $D_{3 h}$ symmetry of the $\mathrm{Cu}_{11}$ core is lowered to $C_{3 h}$ symmetry when the outer ligand sphere is considered. It is of note that, not considering the encapsulated atoms, the structure adopted by 1-3 is similar to that of the above-mentioned clusters $\quad\left[\mathrm{Cu}_{11}\left(\mu_{9}-\mathrm{E}\right)\left(\mu_{3}-\mathrm{X}\right)_{3}\left\{\mathrm{Se}_{2} \mathrm{P}(\mathrm{OR})_{2}\right\}_{6}\right] \quad$ and $\quad\left[\mathrm{Cu}_{11}\left(\mu_{9}-\mathrm{X}\right)\left(\mu_{3^{-}}\right.\right.$ $\left.\mathrm{X})_{3}\left\{\mathrm{Se}_{2} \mathrm{P}(\mathrm{OR})_{2}\right\}_{6}\right]^{+}(\mathrm{E}=\mathrm{S}$, Se; $\mathrm{X}=$ halogen $),{ }^{9-11}$ with the three $\mu_{3}-\mathrm{X}$ halides replaced by the three alkynyl ligands. The $\mathrm{Cu}_{6}$ trigonal prism in 1-3 displays slightly longer intra-triangular edge lengths than the distances of inter-triangular planes. For example, the intra $\mathrm{Cu}_{\mathrm{tri}}-\mathrm{C}_{\mathrm{tri}}$ distances are approximately $0.2 \AA$ longer than inter $\mathrm{Cu}_{\mathrm{tri}}-\mathrm{C}_{\text {tri }}$ distances (see Table 1). Other distances such as $\mathrm{Cu}_{\mathrm{top}}-\mathrm{Cu}_{\mathrm{tri}}, \mathrm{Cu}_{\mathrm{cap}}-\mathrm{Cu}_{\mathrm{tri}}$, and $\mathrm{Cu}-\mathrm{S}$ are almost identical.

(a)

(c)
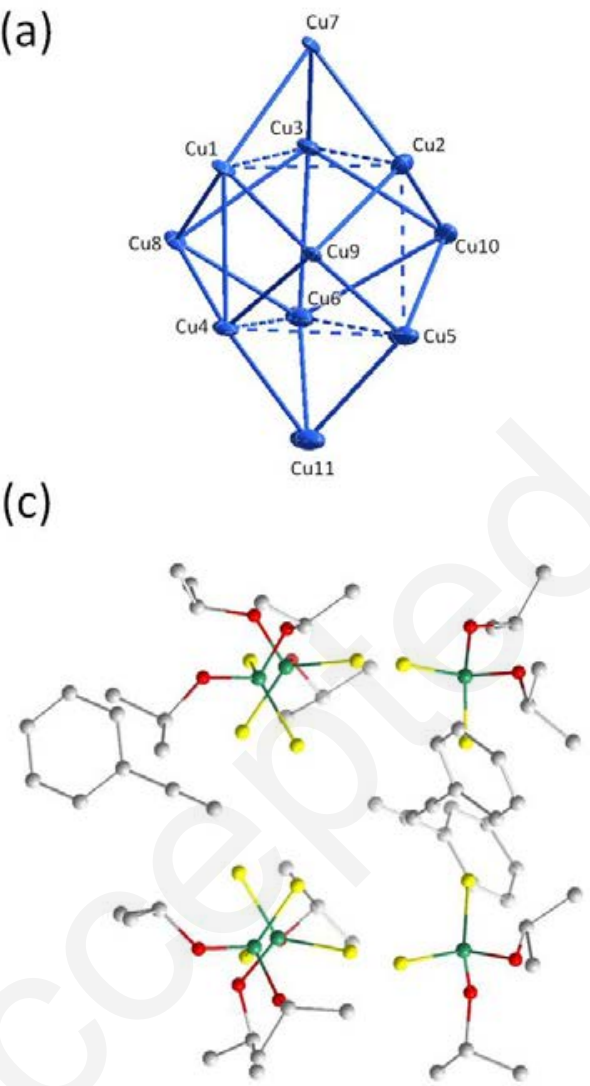

(b)

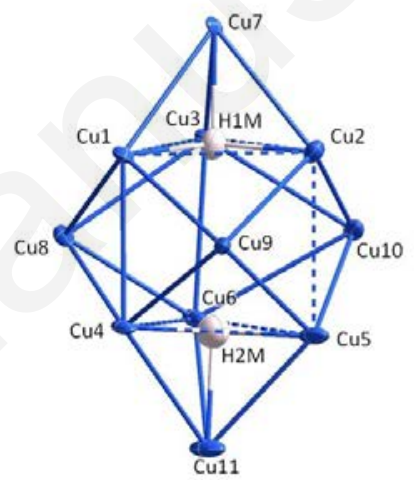

(d)

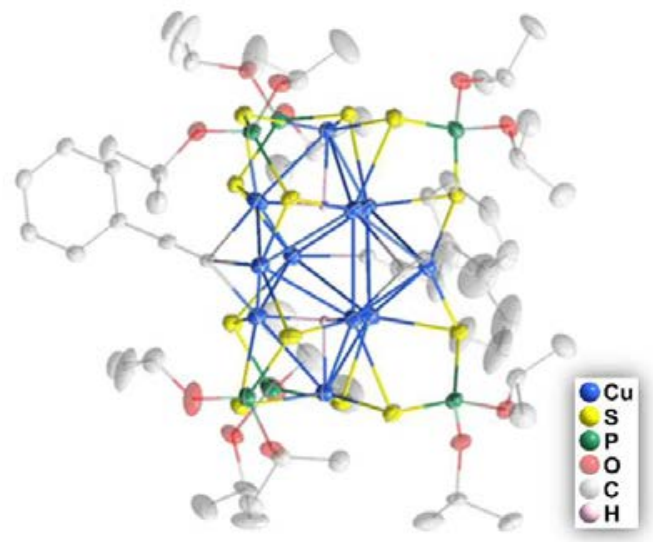

Figure 3. Shell by shell constructions of clusters $\left[\mathrm{Cu}_{11}(\mathrm{H})_{2}\left\{\mathrm{~S}_{2} \mathrm{P}\left(\mathrm{O}^{i} \mathrm{Pr}\right)_{2}\right\}_{6}(\mathrm{C} \equiv \mathrm{CR})_{3}\right]$, where $\mathrm{R}=\mathrm{Ph}$ (1), $\mathrm{C}_{8} \mathrm{H}_{4} \mathrm{~F}$ (2) and $\mathrm{C}_{9} \mathrm{H}_{7} \mathrm{O}$ (3) a). A $\mathrm{Cu}_{11}$ cage in pentacapped trigonal prism; b) Two hydrides encapsulate the $\mathrm{Cu}_{11}$ cage; c) six dithiophosphate and three alkyne ligands; d) Total structure of $\left[\mathrm{Cu}_{11}(\mathrm{H})_{2}\left\{\mathrm{~S}_{2} \mathrm{P}\left(\mathrm{O}^{i} \mathrm{Pr}\right)_{2}\right\}_{6}(\mathrm{C} \equiv \mathrm{CR})_{3}\right]$. 


\begin{tabular}{|c|c|c|c|c|c|c|c|c|}
\hline Comp. & $\mathbf{C u}_{\text {tri }}-\mathbf{H}$ & $\mathbf{C u}_{\text {top }}-\mathbf{H}$ & $\begin{array}{l}\mathrm{Cu}_{\text {tri }}-\mathrm{Cu}_{\text {tri }} \text { intra } \\
\mathrm{Cu}_{\text {tri }}-\mathbf{C} \mathbf{u}_{\text {tri }} \text { inter }\end{array}$ & $\mathrm{Cu}_{\text {top }}-\mathrm{Cu}_{\text {tri }}$ & $\mathbf{C u}_{\text {cap }}-\mathrm{Cu}_{\text {tri }}$ & Cu-S & $\mathrm{Cu}-\mathrm{C}$ & $C \equiv C$ \\
\hline 1 & $\begin{array}{l}\text { 1.69(4)-1.80(4), } \\
\text { avg. 1.75(3) }\end{array}$ & $\begin{array}{l}\text { 1.82(3)-1.98(4), } \\
\text { avg. 1.89(3) }\end{array}$ & $\begin{array}{l}\text { 2.9583(6)-3.1667(9), } \\
\quad \text { avg. 3.0284(6); } \\
\text { 2.7763(5)-2.9245(5), } \\
\quad \text { avg. 2.8352(5) }\end{array}$ & $\begin{array}{l}\text { 2.5828(5)-2.6274(5), } \\
\text { avg. 2.6066(5) }\end{array}$ & $\begin{array}{l}\text { 2.5391(5)-2.8400(5), } \\
\text { avg. } 2.712(5)\end{array}$ & $\begin{array}{l}\text { 2.2801(8)-2.6193(8), } \\
\text { avg. 2.3838(8) }\end{array}$ & $\begin{array}{l}\text { 1.951(3)-2.131(3), } \\
\text { avg. 2.044(3) }\end{array}$ & $\begin{array}{l}\text { 1.181(4)-1.220(4), } \\
\text { avg. 1.206(4) }\end{array}$ \\
\hline $\mathbf{1}_{\mathrm{N}}$ & $\begin{array}{c}\text { 1.737(19)-1.793(17), } \\
\text { avg. } 1.76(2)\end{array}$ & $\begin{array}{l}\text { 1.841(19), 1.860(17) } \\
\text { avg. 1.851(18) }\end{array}$ & $\begin{array}{l}\text { 2.989(11)-3.17(1), } \\
\quad \text { avg. 3.05(1) } \\
\text { 2.771(8)-2.902(9), } \\
\text { avg. 2.842(8) }\end{array}$ & $\begin{array}{l}\text { 2.556(9)-2.659(11), } \\
\text { avg. 2.601(10) }\end{array}$ & $\begin{array}{l}\text { 2.509(8)-2.892(9), } \\
\text { avg. 2.718(10) }\end{array}$ & $\begin{array}{l}\text { 2.24(2)-2.618(16), } \\
\quad \text { avg. 2.38(2) }\end{array}$ & $\begin{array}{l}\text { 1.951(11)-2.158(9), } \\
\text { avg. 2.043(10) }\end{array}$ & $\begin{array}{c}1.201(11)- \\
1.204(10) \\
\text { avg. } 1.203(11)\end{array}$ \\
\hline 1' (DFT) & $\begin{array}{l}\text { 1.714-1.784, } \\
\text { avg. } 1.749\end{array}$ & $\begin{array}{l}\text { 1.880-1.896, } \\
\text { avg. 1.888 }\end{array}$ & $\begin{array}{l}\text { 2.854-3.221, } \\
\text { avg. } 3.024 \\
\text { 2.903-2.958, } \\
\text { avg. } 2.932\end{array}$ & $\begin{array}{l}\text { 2.566-2.609, } \\
\text { avg. 2.584 }\end{array}$ & $\begin{array}{l}\text { 2.531-3.087, } \\
\text { avg. 2.773 }\end{array}$ & $\begin{array}{l}\text { 2.290-2.709, } \\
\text { avg. 2.402 }\end{array}$ & $\begin{array}{l}\text { 1.944-2.160, } \\
\text { avg. 2.044 }\end{array}$ & $\begin{array}{l}1.237-1.238 \\
\text { avg. } 1.238\end{array}$ \\
\hline 2 & $\begin{array}{l}\text { 1.66(5)-1.87(5), } \\
\text { avg. 1.77(5) }\end{array}$ & $\begin{array}{l}1.78(4)-1.89(5), \\
\text { avg. 1.85(5) }\end{array}$ & $\begin{array}{l}\text { 2.9644(7)-3.195(1), } \\
\text { avg. 3.049(1) } \\
\text { 2.7550(6)-2.9370(6), } \\
\text { avg. 2.8631(6) }\end{array}$ & $\begin{array}{c}2.5464(6)-2.6417(6), \\
\text { avg. } 2.6098(6)\end{array}$ & $\begin{array}{c}2.5425(6)-3.0179(6), \\
\text { avg. } 2.7439(6)\end{array}$ & $\begin{array}{l}\text { 2.2784(9)-2.7153(11), } \\
\text { avg. 2.3858(9) }\end{array}$ & $\begin{array}{l}\text { 1.930(4)-2.157(4), } \\
\text { avg. } 2.044(3)\end{array}$ & $\begin{array}{c}\text { 1.185(5)-1.223(5), } \\
\text { avg. 1.209(5) }\end{array}$ \\
\hline 3 & $\begin{array}{l}\text { 1.72(4)-1.80(4), } \\
\text { avg. 1.76(4) }\end{array}$ & $\begin{array}{l}\text { 1.88(4)- 2.04(4), } \\
\text { avg. 1.96(4) }\end{array}$ & $\begin{array}{c}\text { 2.9953(5)-3.1004(6), } \\
\text { avg. 3.0468(6); } \\
\text { 2.7366(4)-2.8527(5), } \\
\text { avg. 2.7808(4) }\end{array}$ & $\begin{array}{l}\text { 2.6021(4)-2.6244(4), } \\
\text { avg. 2.6154(4) }\end{array}$ & $\begin{array}{c}2.5762(4)-2.8344(4) \\
\text { avg. } 2.7125(4)\end{array}$ & $\begin{array}{c}2.3002(6)-2.5896(7) \\
\text { avg. } 2.3902(7)\end{array}$ & $\begin{array}{l}\text { 1.950(3)-2.125(3), } \\
\text { avg. } 2.046(2)\end{array}$ & $\begin{array}{l}\text { 1.214(4)-1.218(4), } \\
\text { avg. 1.216(4) }\end{array}$ \\
\hline $\begin{array}{c}3 \\
\text { (DFT) }\end{array}$ & $\begin{array}{l}\text { 1.732-1.744, } \\
\text { avg. } 1.738\end{array}$ & $\begin{array}{l}\text { 1.896-1.905, } \\
\text { avg. 1.901 }\end{array}$ & $\begin{array}{l}\text { 2.952-3.069, } \\
\text { avg. } 3.009 \\
\\
2.755-2.814 \\
\text { avg. } 2.776\end{array}$ & $\begin{array}{l}\text { 2.580-2.622, } \\
\text { avg. 2.601 }\end{array}$ & $\begin{array}{l}\text { 2.568-2.793, } \\
\text { avg. 2.697 }\end{array}$ & $\begin{array}{c}\text { 2.310-2.529, } \\
\text { avg. } 2.389\end{array}$ & $\begin{array}{l}\text { 1.956-2.139, } \\
\text { avg. 2.044 }\end{array}$ & $\begin{array}{l}\text { 1.230-1.232, } \\
\text { avg. } 1.231\end{array}$ \\
\hline
\end{tabular}

Table 1. Selected bond lengths ( $\AA$ ) for $\mathbf{1}, \mathbf{2}$, and $\mathbf{3}$ (X-ray data), $\mathbf{1}_{\mathrm{N}}$ (neutron data), 1' and $\mathbf{3}$ (DFT). 
Table 2. Selected crystallographic data of $\mathbf{1 - 3}$ (X-ray) and $2\left[\mathbf{1}_{\mathrm{N}}\right] .\left[\mathbf{4}_{\mathrm{N}}\right]$ (neutron).

\begin{tabular}{|c|c|c|c|c|}
\hline & 1 & 2 & $\begin{array}{l}\text { 3. } 2\left(\mathrm{C}_{6} \mathrm{H}_{14}\right) \text {. } \\
\left.\left[\left(\mathrm{CH}_{3}\right)_{2} \mathrm{CO}\right)\right]\end{array}$ & $\begin{array}{l}2\left[\mathbf{1}_{\mathbf{N}}\right] \cdot\left[\mathbf{4}_{\mathbf{N}}\right] \\
\left.2\left[\left(\mathrm{CH}_{3}\right)_{2} \mathrm{CO}\right)\right]\end{array}$ \\
\hline CCDC number & 1961353 & 1961354 & 1961355 & 1967640 \\
\hline Empirical formula & $\mathrm{C}_{60} \mathrm{H}_{101} \mathrm{Cu}_{11} \mathrm{O}_{12} \mathrm{P}_{6} \mathrm{~S}_{12}$ & $\begin{array}{l}\mathrm{C}_{363} \mathrm{H}_{593.20} \mathrm{Cu}_{66} \mathrm{~F}_{18} \mathrm{O}_{73} \mathrm{P}_{36} \\
\mathrm{~S}_{72.4}\end{array}$ & $\mathrm{C}_{78} \mathrm{H}_{141} \mathrm{Cu}_{11} \mathrm{O}_{16} \mathrm{P}_{6} \mathrm{~S}_{12}$ & $\mathrm{C}_{164} \mathrm{H}_{300} \mathrm{Cu}_{29} \mathrm{O}_{38} \mathrm{P}_{18} \mathrm{~S}_{36}$ \\
\hline Formula weight & 2283.88 & 14097.24 & 2604.38 & 6434.30 \\
\hline Temperature, K & $150(2)$ & $150(2)$ & $150(2)$ & $100(2)$ \\
\hline Wavelength, $\AA$ & 0.71073 & 0.71073 & 0.71073 & $0.4-3.5$ \\
\hline Crystal system & Triclinic & Monoclinic & Triclinic & Triclinic \\
\hline Space group & $P(-) 1$ & $P 2_{1} / n$ & $P(-) 1$ & $P(-) 1$ \\
\hline a, $\AA$ & $14.9244(14)$ & $23.7795(10)$ & $14.9538(6)$ & $14.5541(5)$ \\
\hline $\mathrm{b}, \AA$ & 26.487(3) & $27.3755(12)$ & $15.0769(6)$ & $19.9817(7)$ \\
\hline c, $\AA$ & 28.342(3) & 41.2995(18) & $27.7010(10)$ & $23.5820(8)$ \\
\hline$\alpha$, deg. & $113.149(2)$ & 90 & $82.7840(10)$ & 105.344(3) \\
\hline$\beta$, deg. & $104.257(2)$ & $90.1670(10)$ & $86.5970(10)$ & 102.635(3) \\
\hline$\gamma$, deg. & $97.301(2)$ & 90 & $61.0810(10)$ & 98.626(3) \\
\hline Volume, $\AA^{3}$ & $9664.2(16)$ & $26885(2)$ & $5423.3(4)$ & $6294.0(4)$ \\
\hline $\mathrm{Z}$ & 4 & 2 & 2 & 1 \\
\hline $\begin{array}{l}\text { Calculated } \\
\text { density, } \mathrm{Mg} \mathrm{m}^{-3}\end{array}$ & 1.570 & 1.741 & 1.595 & 1.698 \\
\hline 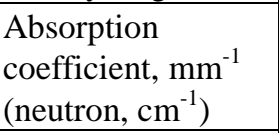 & 2.772 & 2.998 & 2.483 & $1.1587+0.8921 \lambda$ \\
\hline Crystal size, $\mathrm{mm}^{3}$ & $0.07 \times 0.08 \times 0.15$ & $0.13 \times 0.23 \times 0.33$ & $0.29 \times 0.36 \times 0.38$ & $0.80 \times 1.24 \times 1.75$ \\
\hline$\theta_{\max }$, deg. & 25.000 & 26.399 & 27.136 & 32.625 \\
\hline $\begin{array}{l}\text { Reflections } \\
\text { collected / unique }\end{array}$ & $\begin{array}{l}86957 / 33948\left(R_{\mathrm{int}}=\right. \\
0.0211)\end{array}$ & $\begin{array}{l}234576 / 55078\left(R_{\mathrm{int}}=\right. \\
0.0427)\end{array}$ & $\begin{array}{l}77464 / 23970\left(R_{\mathrm{int}}=\right. \\
0.0229)\end{array}$ & $\begin{array}{l}20644 / 10153\left(R_{\text {int }}=\right. \\
0.1249)\end{array}$ \\
\hline Completeness, \% & 99.7 & 100.0 & 100.0 & 38.8 \\
\hline $\begin{array}{l}\text { restraints / } \\
\text { parameters }\end{array}$ & 947 / 1893 & 1320 / 3026 & $522 / 1147$ & 4707 / 2513 \\
\hline GoF & 1.068 & 1.024 & 1.064 & 1.127 \\
\hline $\begin{array}{l}\text { Final } \mathrm{R} \text { indices } \\
{[\mathrm{I}>2 \sigma(\mathrm{I})]}\end{array}$ & $\begin{array}{l}R 1=0.0268, w R 2= \\
0.0678\end{array}$ & $\begin{array}{l}R 1=0.0346, w R 2= \\
0.0747\end{array}$ & $\begin{array}{l}R 1=0.0307, w R 2= \\
0.0745\end{array}$ & $\begin{array}{l}R 1=0.1425, w R 2= \\
0.2718\end{array}$ \\
\hline $\begin{array}{l}\mathrm{R} \text { indices (all } \\
\text { data) }\end{array}$ & $\begin{array}{l}R 1=0.0341, w R 2= \\
0.0703\end{array}$ & $\begin{array}{l}R 1=0.0522, w R 2= \\
0.0810\end{array}$ & $\begin{array}{l}R 1=0.0343, w R 2= \\
0.0762\end{array}$ & $\begin{array}{l}R 1=0.1427, w R 2= \\
0.2722\end{array}$ \\
\hline $\begin{array}{l}\text { Largest diff. peak } \\
\text { / hole, e } \AA^{-3} \\
\text { (neutron, } \mathrm{fm} \text { ) }\end{array}$ & 1.389, -0.797 & $3.568,-2.465$ & $2.345,-0.910$ & $1.235,-0.903$ \\
\hline
\end{tabular}


The precise hydride positions were ascertained by a single-crystal neutron diffraction study of a co-crystallized compound labeled $\left.2\left[\mathbf{1}_{\mathrm{N}}\right] .\left[\mathbf{4}_{\mathrm{N}}\right] .2\left[\left(\mathrm{CH}_{3}\right)_{2} \mathrm{CO}\right)\right]$, which contains two clusters $\left[\mathrm{Cu}_{11}(\mathrm{H})_{2}\left\{\mathrm{~S}_{2} \mathrm{P}\left(\mathrm{O}^{i} \mathrm{Pr}\right)_{2}\right\}_{6}(\mathrm{C} \equiv \mathrm{CPh})_{3}\right]$ (1), one $\left[\mathrm{Cu}_{7}(\mathrm{H})\left\{\mathrm{S}_{2} \mathrm{P}\left(\mathrm{O}^{i} \mathrm{Pr}\right)_{2}\right\}_{6}\right]$ (4), and two acetone molecules in the asymmetric unit. The hydride atoms were located in the nuclear density map and refined anisotropically. The OMIT map in Figure 4a shows the distribution of negative nuclear densities of the two hydrides. They occupy symmetrical positions in each of the (top and bottom) metal tetrahedral cavity composed of a prismatic triangular face and its capping atom. Surprisingly, they do not sit at the tetrahedron center, but instead are lying almost in the plane of the triangular face, as indicated by the sum of the $\mathrm{Cu}_{\text {tri- }}-\mathrm{H}-\mathrm{Cu}_{\text {tri }}$ angles, which is close to 360 degree (Figure 4). As far as we know, this trigonal pyramidal coordination mode of hydrides characterized by neutron diffraction is unprecedented. Indeed the coordination environment of a four-coordinate hydride is mostly in tetrahedral or near square-planar geometry. ${ }^{1}$ The $\mathrm{Cu}-\mathrm{H}$ distances reflect the trigonal pyramidal coordination with two types of $\mathrm{Cu}-\mathrm{H}$ distances, $\mathrm{Cu}_{\mathrm{tri}}-\mathrm{H}$ (average 1.76(2) $\AA$ ) and $\mathrm{Cu}_{\text {top }}-\mathrm{H}$ (average 1.851(18) $\AA$ ). Selected bond lengths of $\mathbf{1}_{\mathbf{N}}$ are listed in Table 1. The ${ }^{31} \mathrm{P}$ NMR resonances of the co-crystals are at 104.16 ppm (1) and 103.95 ppm (4) in a 2:1 ratio (Figure S35). The overall composition of [2(1)(4)] was further characterized by ESImass spectrometry (Figure S36).

(a)

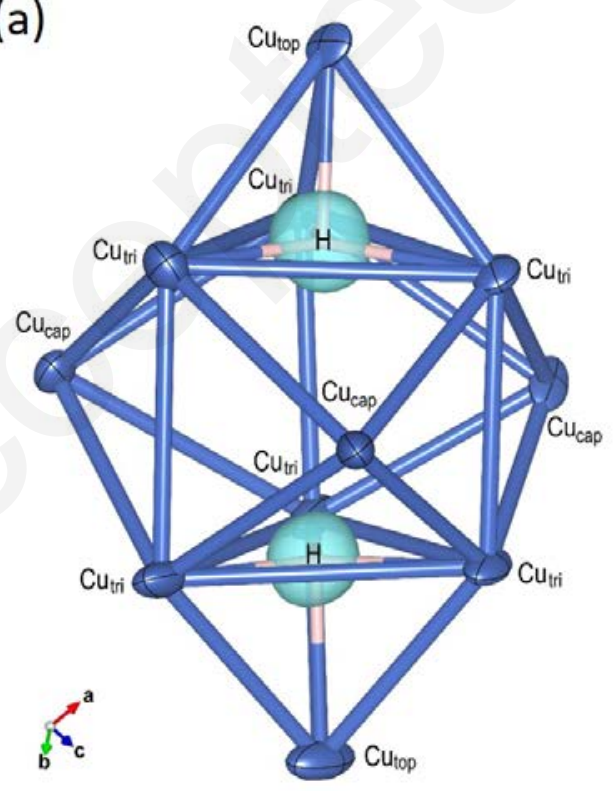

(b)

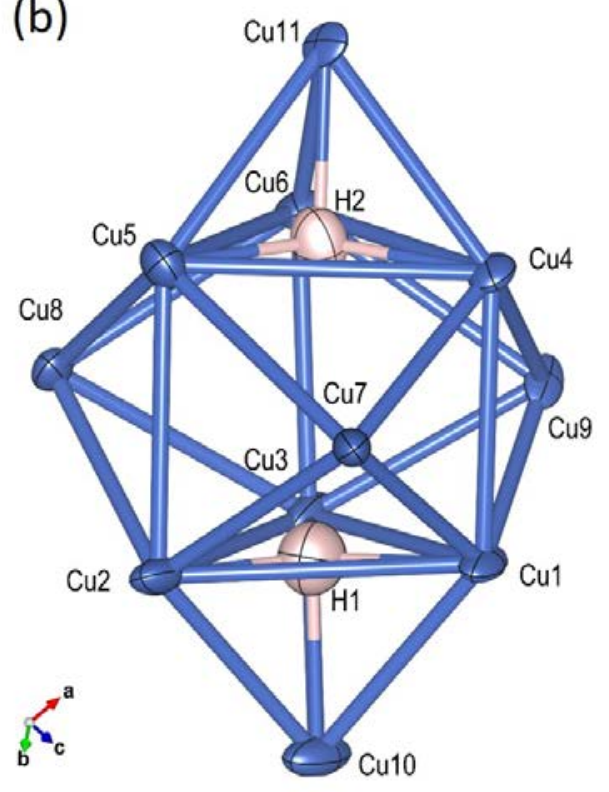


Figure 4. (a) Overlay of the omit map showing the negative nuclear scattering density of the missing hydride atoms in the $\mathrm{Cu}_{11} \mathrm{H}_{2}$ core of $\mathbf{1}_{\mathbf{N}}$ (neutron data). (b) View of the hydride atoms in the $\mathrm{Cu}_{11} \mathrm{H}_{2}$ core of $\mathbf{1}_{\mathbf{N}}$ showing the atom labeling scheme. Atomic displacement ellipsoids are drawn at their 50\% probability level. Color code: $\mathrm{Cu}$, blue; $\mathrm{H}$, pink; nuclear density, cyan. The nuclear density is displayed at isosurface level of $-1.0 \mathrm{fm} \AA^{-3}$. Selected geometric parameters $(\AA$; ○): H1-Cu1 1.751(19), H1-Cu2 1.78(2), H1-Cu3 1.77(2), H1-Cu10 1.841(19); H2-Cu4 1.793(17), H2-Cu5 1.741(17), H2-Cu6 1.737(19), H2-Cu11 1.860(17); Cu1-H1-Cu3 116.5(12), Cu1-H1-Cu2 117.0(13), Cu3-H1-Cu2 126.1(11), Cu1-H1-Cu10 90.7(9), Cu3-H1Cu10 94.9(11), Cu2-H1-Cu10 90.8(9), Cu6-H2-Cu5 118.5(9), Cu6-H2-Cu4 122.7(9), Cu5H2-Cu4 118.4(10), Cu6-H2-Cu11 92.7(8), Cu5-H2-Cu11 91.0(8), Cu4-H2-Cu11 92.2(8). Displacement of hydride atoms from the plane defined by each of the three $\mathrm{Cu}_{\text {tri }}$ atoms: -

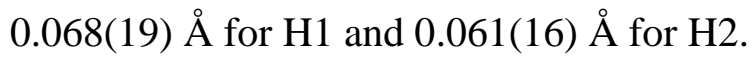

The $\left[\mathrm{Cu}_{11}(\mathrm{H})_{2}\left\{\mathrm{~S}_{2} \mathrm{P}\left(\mathrm{O}^{i} \mathrm{Pr}\right)_{2}\right\}_{6}(\mathrm{C} \equiv \mathrm{CR})_{3}\right]$ clusters look yellowish to the naked eye and have similar absorption features. Clusters 1, 2 and $\mathbf{3}$ display two intense prominent absorption bands at 344 and $414 \mathrm{~nm}$ for 1, 343 and $414 \mathrm{~nm}$ for 2 and 344 and $411 \mathrm{~nm}$ for 3 (Figure 5). The compound $\left[(\mathbf{1})_{2}(4)\right]$ containing the co-crystallized 1 and 4 clusters in the solid state is also yellowish and its spectrum shows the distinguished absorption of both components (Figure S37), i.e., two absorption bands characteristic of 4 at $286 \mathrm{~nm}$ and $348 \mathrm{~nm}$ and a broad absorption band around $418 \mathrm{~nm}$ for $\mathbf{1}$. Monitoring the stability of $\mathbf{1}$ in dichloromethane by UV-Vis at ambient temperature indicates it changes steadily over time and completely decomposes within 5 days (Figure S38). Furthermore, the variable temperature ${ }^{1} \mathrm{H}$ NMR spectra show that resonances corresponding to the alkyl groups of dtp and phenylacetylene moieties remain unchanged and the two hydrides peaks at $4.86 \mathrm{ppm}$ still exist during heating process (Figure S39). This result indicates that $\mathbf{1}$ is stable at elevated temperature. 


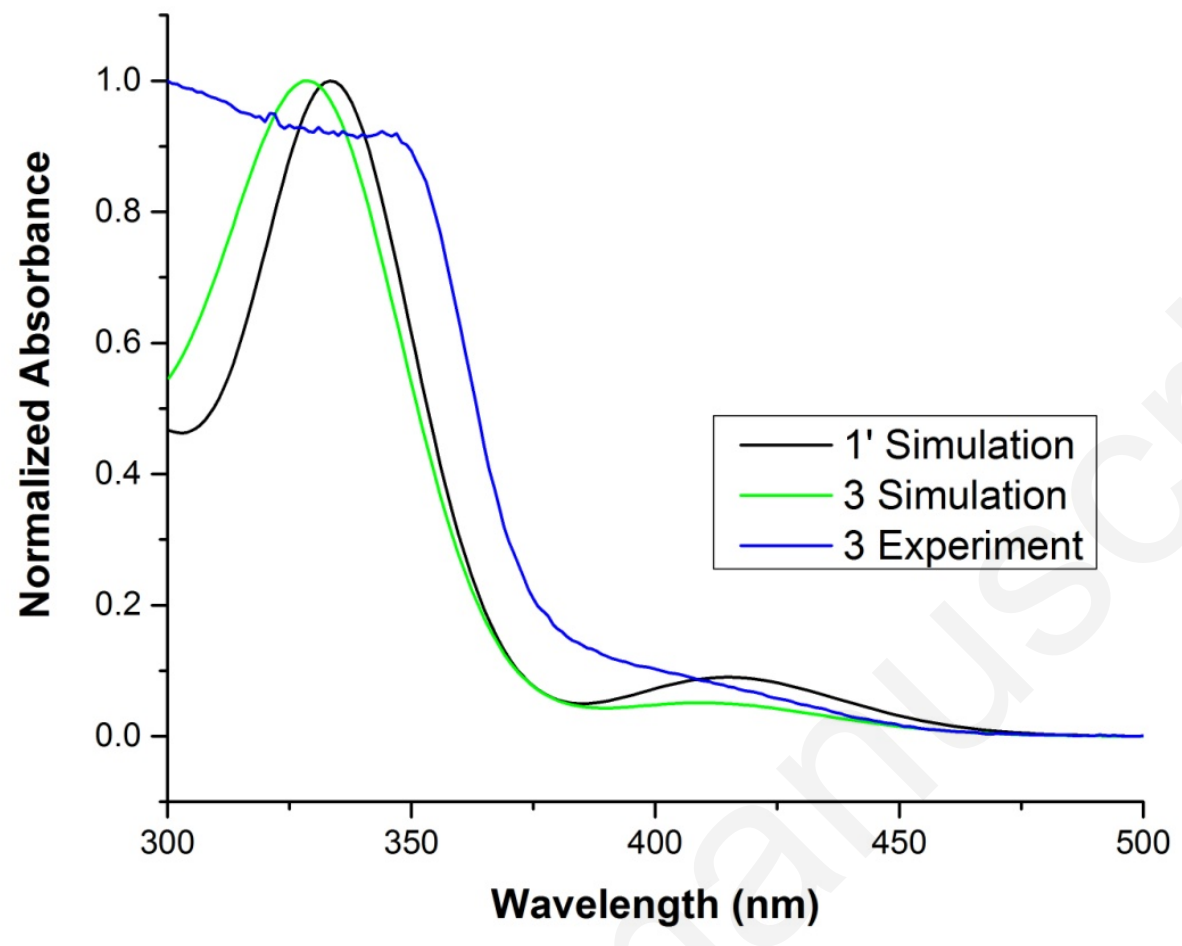

Figure 5. The absorption spectra of cluster 3 in dichloromethane $\left(1.07 \times 10^{-5} \mathrm{M}\right)$ and calculated spectra of $\mathbf{1}$ ' and 3.

DFT calculations carried out at the PBE0/Def2TZVP level were performed both on a simplified model of compounds 1-3, namely $\left[\mathrm{Cu}_{11}(\mathrm{H})_{2}\left(\mathrm{~S}_{2} \mathrm{PH}_{2}\right)_{6}\left(\mathrm{C}_{2} \mathrm{Ph}\right)_{3}\right]\left(\mathbf{1}^{\prime}\right)$ and on the cluster $\mathbf{3}$. Their optimized geometries were found to be of $C_{i}$ symmetry, the deviation away from ideal $C_{3 h}$ symmetry being mainly due to space filling of the ligand substituents. Their metric data are fully consistent with their experimental counterparts in clusters 1-3 (Table 1). It is noteworthy that the trigonal pyramidal coordination mode of the hydrides found by neutron diffraction is unambiguously reproduced by DFT. Other hydride positions were tested in the case 1'. Any trial to encapsulate them in other cavities ended up with the optimized geometry of the global energy minimum, i.e. encapsulated hydrides along the pseudo- $C_{3}$ axis in trigonal pyramidal coordination, presumably in part because of the larger size of these alternative 5-atom cavities, but overall for orbital matching requirement (see below). Similar results were obtained when looking for hydride outer capping positions. A unique alternative energy minimum was found with the hydrides bonded in terminal positions to the $\mathrm{Cu}_{\text {top }}$ atoms lying on the $C_{3}$ axis. This high- 
energy isomer was found to lie $4.48 \mathrm{eV}$ above the global minimum and thus has virtually no chance to be observed. The large HOMO-LUMO gaps of $\mathbf{1}^{\prime}$ and 3 (3.72 and $3.70 \mathrm{eV}$, respectively) are typical for stable $\mathrm{Cu}(\mathrm{I})$ hydride nanoclusters. ${ }^{\mathrm{b}-\mathrm{f}}$

Table 3. Selected NAO charges and interatomic Wiberg indices computed for 1'.

\begin{tabular}{|c|c|c|}
\hline \multirow{4}{*}{ NAO charges } & $\mathrm{Cu}_{\text {tri }}$ & 0.74 \\
\cline { 2 - 3 } & $\mathrm{Cu}_{\text {top }}$ & 0.68 \\
\cline { 2 - 3 } & $\mathrm{Cu}_{\text {cap }}$ & 0.74 \\
\cline { 2 - 3 } & $\mathrm{H}$ (hydrides) & -0.69 \\
\hline \multirow{5}{*}{ Wiberg indices } & $\mathrm{Cu}_{\text {tri }}-\mathrm{H}$ & 0.097 \\
\cline { 2 - 3 } & $\mathrm{Cu}_{\text {top }}-\mathrm{H}$ & 0.070 \\
\cline { 2 - 3 } & $\mathrm{Cu}_{\text {tri }}-\mathrm{Cu}_{\text {tri }}$ & 0.025 \\
\cline { 2 - 3 } & $\mathrm{Cu}_{\text {top }}-\mathrm{Cu}_{\text {tri }}$ & 0.040 \\
\cline { 2 - 3 } & $\mathrm{Cu}_{\text {cap }}-\mathrm{Cu}_{\text {tri }}$ & 0.032 \\
\cline { 2 - 3 } & $\mathrm{Cu}-\mathrm{S}$ & 0.157 \\
\cline { 2 - 3 } & $\mathrm{Cu}-\mathrm{C}$ & 0.178 \\
\cline { 2 - 3 } & $\mathrm{C} \equiv \mathrm{C}$ & 2.624 \\
\hline
\end{tabular}

Since $\mathbf{1}$ ' and $\mathbf{3}$ provided very similar results, we focus below on those of $\mathbf{1}^{\prime}$. Its Kohn-Sham orbital diagram is shown in Figure 6. The highest occupied levels have a dominant $3 \mathrm{~d}(\mathrm{Cu})$ character with negligible hydride participation. The three lowest unoccupied orbitals are the combination of "in-plane" $\pi^{*}(\mathrm{CC})$ orbitals of the phenyl alkynyl ligands. They are delocalized on both the CC triple bonds and the 6-membered rings with minor metal admixtures. The natural atomic orbital (NAO) charges of the copper atoms $(\sim+0.7$, see Table 3$)$ and of the hydrides ( $0.7)$ are also typical for stable $\mathrm{Cu}(\mathrm{I})$ hydride nanoclusters. ${ }^{\text {lb-f }}$ The particularly small $\mathrm{Cu}-\mathrm{Cu}$ Wiberg indices are consistent with the mainly metallophilic character of these weak interactions. The $\mathrm{Cu}-\mathrm{H}$ Wiberg indices indicate stronger bonding with the in-plane $\mathrm{Cu}_{\text {tri }}$ atoms, in line with their shorter $\mathrm{Cu}-\mathrm{H}$ distances (Table 1). 


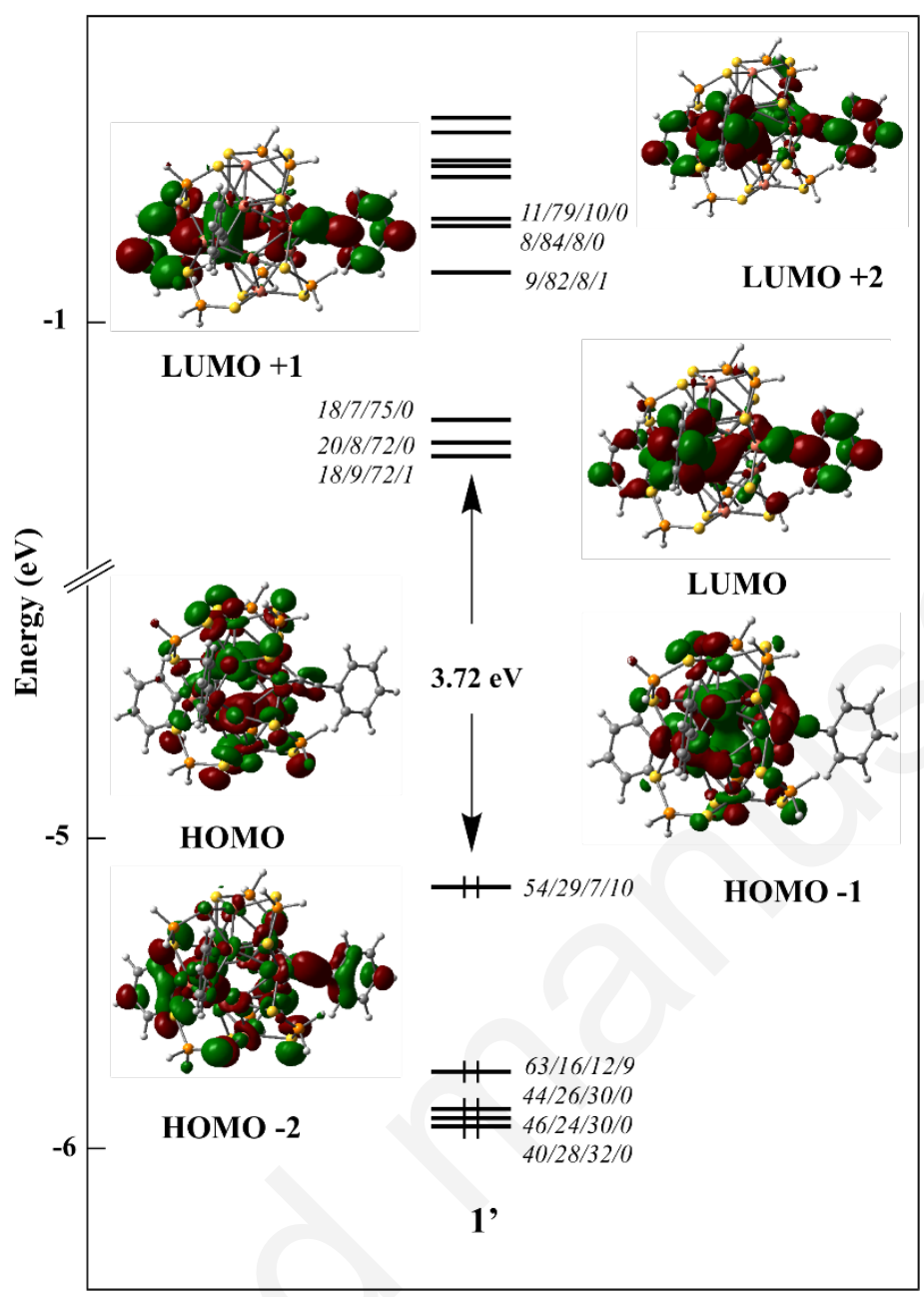

Figure 6. Kohn-Sham frontier orbital diagram of cluster 1' with localization (\%) in the order $\mathrm{Cu}_{11} /\left(\mathrm{S}_{2} \mathrm{PH}_{2}\right)_{6} /\left(\mathrm{C}_{2} \mathrm{Ph}\right)_{3} / \mathrm{H}_{2}$.

An analysis of the bonding of the two hydrides with their $\left[\mathrm{Cu}_{11}\left(\mathrm{~S}_{2} \mathrm{PH}_{2}\right)_{6}\left(\mathrm{C}_{2} \mathrm{Ph}\right)_{3}\right]^{2+}$ host cage in 1' leads to a very simple 2-electron/2-orbital picture: both in-phase and out-of-phase combinations of the occupied $1 \mathrm{~s}(\mathrm{H})$ orbitals interact in a one-to-one fashion with the LUMO and $\mathrm{LUMO}+1$ of $\left[\mathrm{Cu}_{11}\left(\mathrm{~S}_{2} \mathrm{PH}_{2}\right)_{6}\left(\mathrm{C}_{2} \mathrm{Ph}\right)_{3}\right]^{2+}$, respectively. These two accepting orbitals (Figure 7) have large $4 \mathrm{~s}(\mathrm{Cu})$ character, both with major localization on the triangular faces of the central copper prisms (49\% and 51\%, respectively) and minor contribution (9\% and 13\%, respectively) on the copper atoms capping these faces. These orbital topologies are responsible for the preference for a nearly trigonal pyramidal hydride coordination mode over the more common tetrahedral one. The larger $\mathrm{Cu}$...Cu distances of the trigonal base $\left(\mathrm{Cu}_{\mathrm{tri}}-\mathrm{Cu}_{\mathrm{tri}}\right.$ intra in Table 1$)$ also favor this preference. 

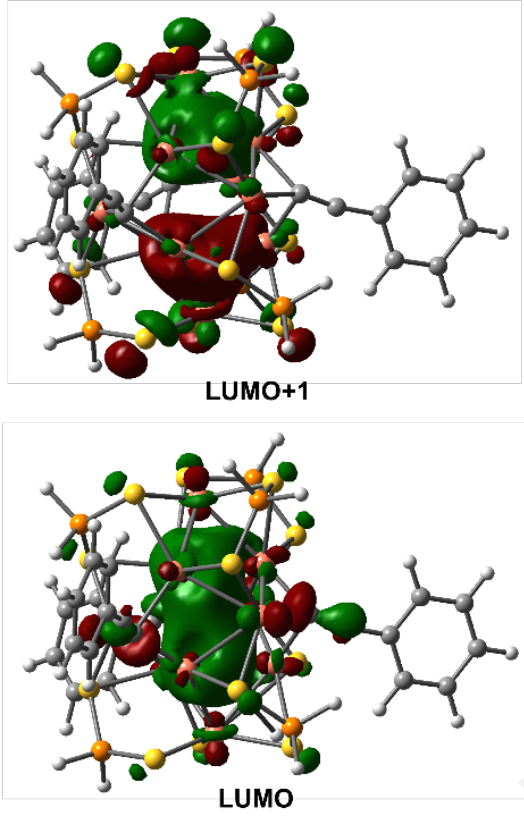

Figure 7. The two accepting orbitals of the hosting cage $\left[\mathrm{Cu}_{11}\left(\mathrm{~S}_{2} \mathrm{PH}_{2}\right)_{6}\left(\mathrm{C}_{2} \mathrm{Ph}\right)_{3}\right]^{2+}$ which are responsible for the bonding with the two encapsulated hydrides.

TD-DFT calculations on 1' found the simulated low-energy weak band (Figure 5) associated with a transition at $415 \mathrm{~nm}$ of $\mathrm{HOMO} \rightarrow \mathrm{LUMO}$ and $\mathrm{HOMO} \rightarrow \mathrm{LUMO}+1$ character, thus of MLCT nature, where L means mainly alkynyl $\pi^{*}(\mathrm{CC})$. The second simulated band is associated with a transition at $333 \mathrm{~nm}$ also of MLCT nature, and involves several 3d(Cu)-type occupied levels and the three lowest vacant orbitals of large alkynyl $\pi^{*}(\mathrm{CC})$ nature. The TD-DFTsimulated spectrum of $\mathbf{3}$ (Figure 5) is very similar to that of $\mathbf{1}$ ', with transitions of the same MLCT nature. 


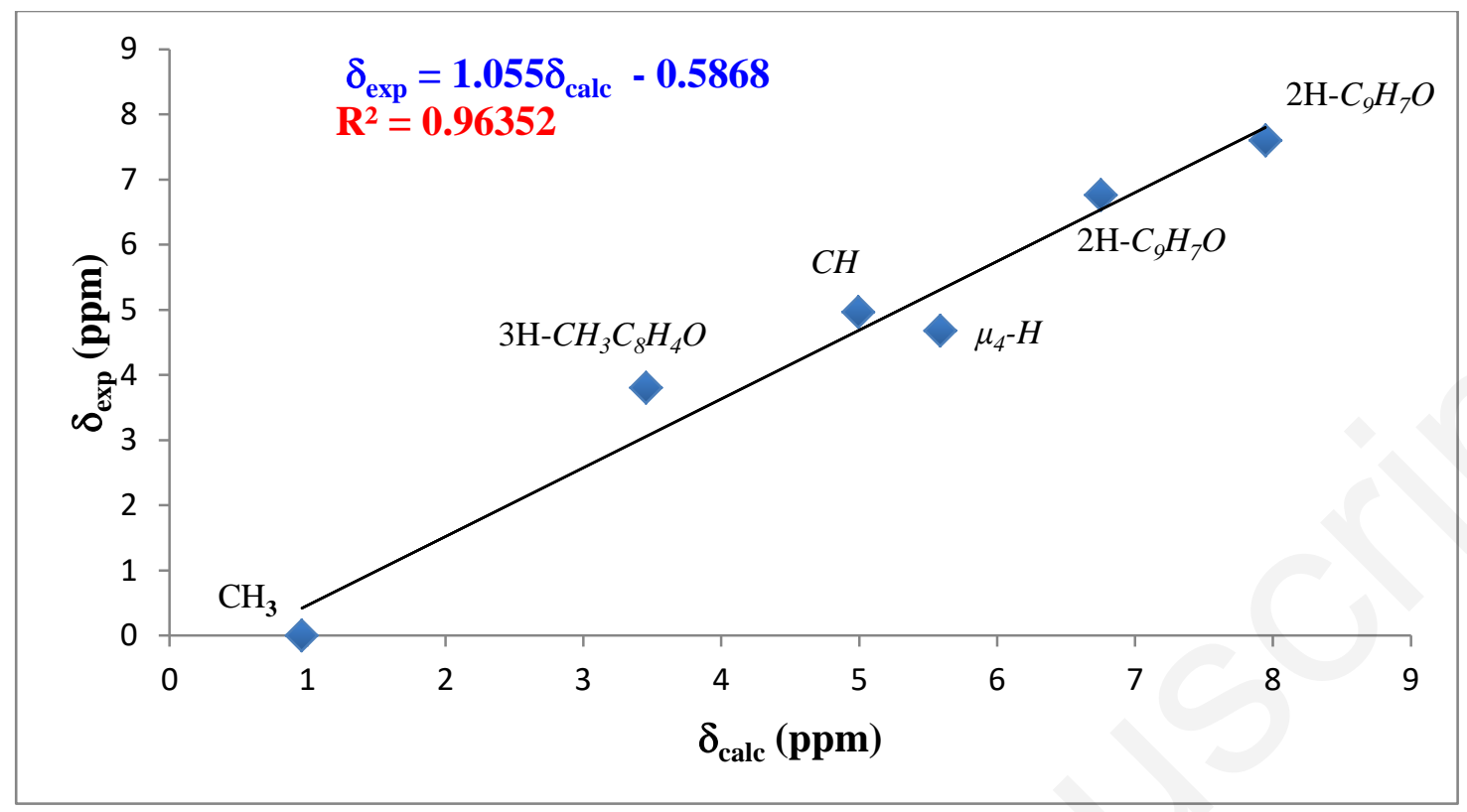

Figure 8. A correlation plot of the experimental vs. computed ${ }^{1} \mathrm{H}$ MNR chemical shifts of 3 .

Finally, it is worthy of noting that the calculated ${ }^{1} \mathrm{H}$ NMR chemical shifts of $\mathbf{3}$ are in good agreement with their experimental counterparts, as exemplified by the linear correlation that exists between the two sets of values (Figure 8). Such a consistency brings supplementary confidence on the existence of the two encapsulated hydrides and on their coordination mode, if there were even the need for. Finally, it should be noted that the calculated $\mathrm{Cu}-\mathrm{H}$ vibrational frequencies were found to lie in two ranges, i.e. $730-790 \mathrm{~cm}^{-1}$ and $1200-1220 \mathrm{~cm}^{-1}$.

\section{CONCLUSIONS}

We have successfully isolated three new clusters, $\left[\mathrm{Cu}_{11}(\mathrm{H})_{2}\left\{\mathrm{~S}_{2} \mathrm{P}\left(\mathrm{O}{ }^{i} \mathrm{Pr}\right)_{2}\right\}_{6}(\mathrm{C} \equiv \mathrm{CR})_{3}\right], \mathrm{R}=\mathrm{Ph}(\mathbf{1})$, $\mathrm{C}_{6} \mathrm{H}_{4} \mathrm{~F}$ (2) and $\mathrm{C}_{6} \mathrm{H}_{4} \mathrm{OMe}$ (3), which contain two hydrides located inside an eleven-copper cage. The $\mathrm{Cu}_{11} \mathrm{H}_{2}$ core is the first example having two interstitial hydrides enclosed in a pentacapped trigonal prismatic copper cage, which is further stabilized by six diisopropyl dithiphosphates and three alkynyl ligands. The two hydrides in $\mathbf{1}$ adopt a $\mu_{4}-\mathrm{H}$ trigonal pyramidal coordination mode, fully authenticated by single crystal neutron diffraction and confirmed by DFT calculations. The fully characterized copper hydrides provide timely examples for the emerging topics of 
nanoscale copper hydrides, ${ }^{14 a-g}$ the hydride position of some of which being not even discussed. ${ }^{14 h-j}$

\section{EXPERIMENTAL SECTIONS}

All chemicals were purchased from commercial sources and used as received. Solvents were purified following standard protocols. All reactions were carried out under $\mathrm{N}_{2}$ atmosphere by using standard Schlenk techniques. $\left[\mathrm{Cu}_{20} \mathrm{H}_{11}\left\{\mathrm{~S}_{2} \mathrm{P}\left(\mathrm{O}^{i} \mathrm{Pr}\right)_{2}\right\}_{9}\right],{ }^{1 \mathrm{e}}\left[\mathrm{Cu}\left(\mathrm{CH}_{3} \mathrm{CN}\right)_{4}\right]\left(\mathrm{PF}_{6}\right),{ }^{15}$ and $\left[\mathrm{NH}_{4}\right]\left[\mathrm{S}_{2} \mathrm{P}\left(\mathrm{O}^{i} \mathrm{Pr}\right)_{2}\right]^{16}$ was prepared by following the procedure reported in literature and characterized. ${ }^{16}$ NMR spectra were recorded on a Bruker Advance DPX300 FT-NMR spectrometer operating at $300 \mathrm{MHz}$ while recording ${ }^{1} \mathrm{H}, 121.5 \mathrm{MHz}$ for ${ }^{31} \mathrm{P}, 100.61 \mathrm{MHz}$ for ${ }^{13} \mathrm{C}$ and $46.1 \mathrm{MHz}$ for ${ }^{2} \mathrm{H}$. The ${ }^{31} \mathrm{P}$ NMR spectra were referenced to external $85 \% \mathrm{H}_{3} \mathrm{PO}_{4}$ at $\delta=0 \mathrm{ppm}$. The chemical shift $(\delta$ ) and coupling constant $(\mathrm{J})$ are reported in ppm and $\mathrm{Hz}$, respectively. ESImass spectrum recorded on a Fison Quattro Bio-Q (Fisons Instruments, VG Biotech, U. K.). UV-Visible absorption spectra were measured on a Perkin Elmer Lambda 750 spectrophotometer using quartz cells with a path length of $1 \mathrm{~cm}$.

\section{General Preparation of $\left[\mathrm{Cu}_{11}(\mathrm{H})_{2}\left\{\mathrm{~S}_{2} \mathrm{P}\left(\mathrm{O}^{i} \mathrm{Pr}\right)_{2}\right\}_{6}(\mathrm{C} \equiv \mathrm{CR})_{3}\right],\left[R=\mathrm{C}_{2} \mathrm{Ph}(1) ; \mathrm{C}_{8} \mathrm{H}_{4} \mathrm{~F}\right.$ (2); $\mathrm{C}_{9} \mathrm{H}_{7} \mathrm{O}$}

(3)]. Cluster 1, 2, and 3 can be prepared by following two general procedures and detailed preparation method is given for cluster 1 for both methods.

Method a (1-3). In a Flame-dried Schlenk tube, $\left[\mathrm{Cu}_{20}(\mathrm{H})_{11}\left\{\mathrm{~S}_{2} \mathrm{P}\left(\mathrm{O}^{i} \mathrm{Pr}\right)_{2}\right\}_{9}\right],(0.1 \mathrm{~g}, 0.031 \mathrm{mmol})$ was suspended in THF $\left(5 \mathrm{~cm}^{3}\right)$ along with phenylacetylene $(31 \mu \mathrm{L}, 0.279 \mathrm{mmol})$ resulting mixture was stirred at $30^{\circ} \mathrm{C}$ for $48 \mathrm{~h}$. The solvent was evaporated under vacuum and residue was dissolved in DCM and washed with water $(3 \times 15 \mathrm{~mL})$. After separation, organic layer was passed through $\mathrm{Al}_{2} \mathrm{O}_{3}$, the yellow residue was dissolved with ether, and solvent was evaporated under vacuum. The precipitate continue to wash with methanol $(3 \times 15 \mathrm{~mL})$, to remove $\left[\mathrm{Cu}_{7} \mathrm{H}\left\{\mathrm{S}_{2} \mathrm{P}\left(\mathrm{O}^{i} \mathrm{Pr}\right)_{2}\right\}_{6}\right]$ and ligands impurities. Finally, solvent was evaporated to dryness under vacuum to get a pure yellow powdered of $\mathbf{1}$. The yield is $0.0655,10.1 \%$ based on $\mathrm{Cu}$.

Similarly, deuterium analog (3) was synthesized by using $\left[\mathrm{Cu}_{20}(\mathrm{D})_{11}\left\{\mathrm{~S}_{2} \mathrm{P}\left(\mathrm{O}^{i} \mathrm{Pr}\right)_{2}\right\}_{9}\right]$, result the formation of $\left[\mathrm{Cu}_{11}(\mathrm{D})_{2}\left\{\mathrm{~S}_{2} \mathrm{P}\left(\mathrm{O}^{i} \mathrm{Pr}\right)_{2}\right\}_{6}\left(\mathrm{C} \equiv \mathrm{CC}_{4} \mathrm{H}_{9} \mathrm{OMe}\right)_{3}\right]$. 
Method b (1-2). In a Flame-dried Schlenk tube $\left[\mathrm{NH}_{4}\right]\left[\mathrm{S}_{2} \mathrm{P}\left\{\mathrm{O}^{i} \mathrm{Pr}\right\}_{2}\right](0.046 \mathrm{~g}, 0.2 \mathrm{mmol})$ and phenylacetylene (43 $\mu \mathrm{L}, 0.4 \mathrm{mmol})$ was suspended in THF $\left(30 \mathrm{~cm}^{3}\right)$, then continue addition of $\left[\mathrm{Cu}\left(\mathrm{CH}_{3} \mathrm{CN}\right)_{4}\right]\left(\mathrm{PF}_{6}\right)(0.112 \mathrm{~g}, 0.35 \mathrm{mmol})$ and Triethylamine $(40 \mu \mathrm{L}, 0.4 \mathrm{mmol})$. After stirred 5 minute, $\mathrm{NaBH}_{4}(0.0037 \mathrm{~g}, 0.1 \mathrm{mmol})$ was added to the mixture. The resulting mixture was stirred at $30^{\circ} \mathrm{C}$ for 3 hours. The solvent was evaporated under vacuum and residue was dissolved in DCM and washed with water $(3 \times 15 \mathrm{~mL})$. After separation, organic layer was passed through $\mathrm{Al}_{2} \mathrm{O}_{3}$, the yellow residue was dissolved with ether, and solvent was evaporated under vacuum. The precipitate continue to wash with methanol $(3 \times 15 \mathrm{~mL})$, to remove $\left[\mathrm{Cu}_{7} \mathrm{H}\left\{\mathrm{S}_{2} \mathrm{P}\left(\mathrm{O}^{i} \mathrm{Pr}\right)_{2}\right\}_{6}\right]$ and ligands impurities. Finally, solvent was evaporated to dryness under vacuum to get a pure yellow powdered of $\mathbf{1}$. The yield is $0.030,48.7 \%$ based on $\mathrm{Cu}$.

Similarly, deuterium analog (1-2) was synthesized by reacting $\mathrm{NaBD}_{4}(0.0042,0.1 \mathrm{mmol})$, result the formation of $\left[\mathrm{Cu}_{11}(\mathrm{D})_{2}\left\{\mathrm{~S}_{2} \mathrm{P}\left(\mathrm{O}{ }^{i} \mathrm{Pr}\right)_{2}\right\}_{6}(\mathrm{C} \equiv \mathrm{CR})_{3}\right]$.

\section{Preparation of 2[1] . [4]}

In a Flame-dried Schlenk tube $\left[\mathrm{NH}_{4}\right]\left[\mathrm{S}_{2} \mathrm{P}\left\{\mathrm{O}^{i} \mathrm{Pr}\right\}_{2}\right](0.046 \mathrm{~g}, 0.2 \mathrm{mmol})$ and phenylacetylene (43 $\mu \mathrm{L}, 0.4 \mathrm{mmol})$ was suspended in THF $\left(30 \mathrm{~cm}^{3}\right)$, then continue addition of $\left[\mathrm{Cu}\left(\mathrm{CH}_{3} \mathrm{CN}\right)_{4}\right]\left(\mathrm{PF}_{6}\right)$ $(0.112 \mathrm{~g}, 0.35 \mathrm{mmol})$ and Triethylamine $(40 \mu \mathrm{L}, 0.4 \mathrm{mmol})$. After stirred 5 minute, $\mathrm{NaBH}_{4}$ ( $0.0037 \mathrm{~g}, 0.1 \mathrm{mmol}$ ) was added to the mixture. The resulting mixture was stirred at $30^{\circ} \mathrm{C}$ for 3 hours. The solvent was evaporated under vacuum and residue was dissolved in DCM and washed with water $(3 \times 15 \mathrm{~mL})$. After extraction, organic layer was collected and passed through $\mathrm{Al}_{2} \mathrm{O}_{3}$ to get yellow residue then dissolved in acetone. Solvent was evaporated under vacuum to get yellow powders of $\mathbf{1}$ and $\mathbf{4}$.

(1 $\left.\mathbf{1}_{\mathbf{H}}\right):$ ESI-MS: $m / z(C a l .2283 .46) 2283.54$ for $\left[\mathrm{Cu}_{11}(\mathrm{H})_{2}\left\{\mathrm{~S}_{2} \mathrm{P}\left(\mathrm{O}^{i} \mathrm{Pr}\right)_{2}\right\}_{6}\left(\mathrm{C} \equiv \mathrm{CC}_{6} \mathrm{H}_{5}\right)_{3}\right]\left(\mathbf{1}_{\mathbf{H}}\right)$ and $\mathrm{m} / \mathrm{z}$ (Cal. 2346.38) 2346.48 for $\left.\left[\mathrm{Cu}_{11}(\mathrm{H})_{2}\left\{\mathrm{~S}_{2} \mathrm{P}\left(\mathrm{O}^{i} \mathrm{Pr}\right)_{2}\right\}_{6}\left(\mathrm{C} \equiv \mathrm{CC}_{6} \mathrm{H}_{5}\right)_{3}\right]+\mathrm{Cu}^{+}\right]^{+}$. ${ }^{1} \mathrm{H} \mathrm{NMR}(300 \mathrm{MHz}$, $\mathrm{CDCl}_{3}$ ):7.21 7.65 (m, $15 \mathrm{H},-\mathrm{C}_{2} \mathrm{Ph}$ ), $5.07 \sim 4.83$ (m, $12 \mathrm{H}, \mathrm{CH}$ ), 4.76 (bs, 2H, $\mu_{4}-H$ ), 1.52 1.38 (d, $\left.72 \mathrm{H}, \mathrm{CH}_{3}\right) \mathrm{ppm} ;{ }^{13} \mathrm{C} \mathrm{NMR}$ (400 MHz, d-Acetone): 135.25, 131.75, 128.12, 124.13, 83.87, 74.58, 74.07, 73.12, 23.31 ppm; ${ }^{31} \mathrm{P}$ NMR (121.49 $\left.\mathrm{MHz}, \mathrm{CDCl}_{3}\right)$ : 103.9 (1 $\left.\mathbf{1}_{\mathbf{H}}\right)$. FT-IR data in $\mathrm{KBr}$ pellet (cm-1 ${ }^{1}$ ): 2975.3; 2931.9; 2870.7; 2009.9; 1722.7; 1592.5; 1483.3; 1177.1; 1140.2 1069.1; 951.7, 884.1; 755.8; 689.6. Elem.Anal: (Cal. C\% 31.55; H\% 4.46). Found: C\% 31.21; H\% 4.50. 
(1) $\mathbf{D}):$ ESI-MS: $m / z$ (Cal. 2283.46) 2285.45 for $\left.\left[\mathrm{Cu}_{11}(\mathrm{D})_{2}\left\{\mathrm{~S}_{2} \mathrm{P}\left(\mathrm{O}^{i} \mathrm{Pr}\right)_{2}\right\}_{6}\left(\mathrm{C} \equiv \mathrm{CC}_{6} \mathrm{H}_{5}\right)_{3}\right]\right)\left(\mathbf{1}_{\mathbf{D}}\right)$ and m/z (Cal. 2346.38) 2348.37 for $\left.\left[\mathrm{Cu}_{11}(\mathrm{D})_{2}\left\{\mathrm{~S}_{2} \mathrm{P}\left(\mathrm{O}^{i} \mathrm{Pr}\right)_{2}\right\}_{6}\left(\mathrm{C} \equiv \mathrm{CC}_{6} \mathrm{H}_{5}\right)_{3}\right]+\mathrm{Cu}^{+}\right]^{+} .{ }^{1} \mathrm{H}$ NMR (300 MHz, $\left.\mathrm{CDCl}_{3}\right)$ :7.20 7.65 (m, $15 \mathrm{H},-\mathrm{C}_{2} \mathrm{Ph}$ ), 5.07 4.82 (m, $12 \mathrm{H}, \mathrm{CH}$ ), 1.52 1.38 (d, $72 \mathrm{H}, \mathrm{CH}_{3}$ ) ppm. ${ }^{2} \mathrm{H}$ NMR (46.1 MHz, $\mathrm{CDCl}_{3}$ ): 4.82 (bs, 2D, $\left.\mu_{4}-\mathrm{D}\right) .{ }^{31} \mathrm{P}$ NMR (121.49 MHz, $\mathrm{CDCl}_{3}$ ): $103.9\left(\mathbf{1}_{\mathbf{H}}\right)$. FT-IR data in KBr pellet ( $\mathrm{cm}^{-1}$ ): 2976.1; 2932.1; 2871.6; 2010.6, 1723.6; 1592.7; 1482.9; 1177.1; 1064.4; m951.6; 884.4; 753.7; 689.7. The precentage yield: 0.032 g, 50.7\% based on $\mathrm{Cu}$.

(2 $\mathbf{H}):$ ESI-MS: $m / z$ (Cal. 2337.43) 2337.49 for $\left[\mathrm{Cu}_{11}(\mathrm{H})_{2}\left\{\mathrm{~S}_{2} \mathrm{P}\left(\mathrm{O}^{i} \mathrm{Pr}\right)_{2}\right\}_{6}\left(\mathrm{C} \equiv \mathrm{CC}_{6} \mathrm{H}_{5} \mathrm{~F}\right)_{3}\right]\left(\mathbf{2}_{\mathbf{H}}\right)$ and $\mathrm{m} / \mathrm{z}$ (Cal. 2400.36) 2400.43 for $\left[\mathrm{Cu}_{11}(\mathrm{H})_{2}\left\{\mathrm{~S}_{2} \mathrm{P}\left(\mathrm{O}^{i} \mathrm{Pr}\right)_{2}\right\}_{6}\left(\mathrm{C} \equiv \mathrm{CC}_{6} \mathrm{H}_{5} \mathrm{~F}\right)+\mathrm{Cu}^{+}\right]^{+} .{ }^{1} \mathrm{H} N \mathrm{NR}(300 \mathrm{MHz}$, $\mathrm{CDCl}_{3}$ ): $6.90 \sim 7.40$ (m, $12 \mathrm{H},-\mathrm{C}_{8} H_{4} F$ ), 5.04 4.82 (m, $12 \mathrm{H}, \mathrm{CH}$ ), 4.76 (bs, $2 \mathrm{H}, \mu_{4}-H$ ), 1.21 1.88 (d, $72 \mathrm{H}, \mathrm{CH}_{3}$ ) ppm; ${ }^{13} \mathrm{C}$ NMR (400 MHz, $d$-Acetone): 159.63, 133.42, 116.68, 81.57, 74.23, 74.07, 72.92, 54.75, $23.31 \mathrm{ppm} ;{ }^{31} \mathrm{P}$ NMR (121.49 MHz,CDCl $)$ ): 103.6. (2 $\mathbf{H}_{\mathrm{H}}$. FT-IR data in $\mathrm{KBr}$ pellet $\left(\mathrm{cm}^{-}{ }^{1}\right)$ : 3063.8; 2977.3; 2932.4; 2871.9; 2001.6; 1601.5 1574.6; 1465.71257.5; 1238.8; 1177.0; 1103.1; 1075.4; 884.3; 746.0;680.1; 529.1 460.2. Elem.Anal: (Cal. C\% 30.82; H\% 4.23). Found: C\% 27.25; H\% 4.46. The precentage yield: 0.030 g, $47.3 \%$ based on $\mathrm{Cu}$.

(2D): ESI-MS: $\mathrm{m} / \mathrm{z}$ (Cal. 2337.43) 2338.52 for $\left[\mathrm{Cu}_{11}(\mathrm{D})_{2}\left\{\mathrm{~S}_{2} \mathrm{P}\left(\mathrm{O}^{i} \mathrm{Pr}\right)_{2}\right\}_{6}\left(\mathrm{C} \equiv \mathrm{CC}_{6} \mathrm{H}_{5} \mathrm{~F}\right)_{3}\right]\left(\mathbf{2}_{\mathbf{D}}\right)$ and $\mathrm{m} / \mathrm{z}$ (Cal. 2400.36) 2402.53 for $\left.\left[\mathrm{Cu}_{11}(\mathrm{D})_{2}\left\{\mathrm{~S}_{2} \mathrm{P}\left(\mathrm{O}^{i} \mathrm{Pr}\right)_{2}\right\}_{6}\left(\mathrm{C} \equiv \mathrm{CC}_{6} \mathrm{H}_{5} \mathrm{~F}\right)_{3}\right]+\mathrm{Cu}^{+}\right]^{+} .{ }^{1} \mathrm{H}$ NMR (300 $\mathrm{MHz}, \mathrm{CDCl}_{3}$ ):6.91 7.39 (m, $\left.12 \mathrm{H},-\mathrm{C}_{2} P h\right), 5.03 \sim 4.82$ (m, $12 \mathrm{H}, \mathrm{CH}$ ), 1.24 1.39 (d, $72 \mathrm{H}, C_{3}$ ) ppm. ${ }^{2} \mathrm{H}$ NMR (46.1 MHz, $\mathrm{CDCl}_{3}$ ): 4.82 (bs, 2D, $\mu_{4}-\mathrm{D}$ ). ${ }^{31} \mathrm{P}$ NMR (121.49 MHz, $\mathrm{CDCl}_{3}$ ): 103.6. (2D). FT-IR data in $\mathrm{KBr}$ pellet $\left(\mathrm{cm}^{-1}\right)$ : 3436.2; 3064.9; 2977.5; 2932.6; 2872.7; 2000.4; 1602.9; 1574.8; 1480.8; 1450.7 1257.6; 1258.6; 1177.7; 1102.5; 1075.0; 934.0; 884.9; 754.9; 680.8; 529.5; 460.0. The precentage yield: 0.035 g, 55.3\% based on $\mathrm{Cu}$.

(3. $\mathbf{3}_{\mathrm{H}}$ : ESI-MS: $m / z$ (Cal. 2373.49) 2373.48 for $\left.\left[\mathrm{Cu}_{11}(\mathrm{H})_{2}\left\{\mathrm{~S}_{2} \mathrm{P}\left(\mathrm{O}^{i} \mathrm{Pr}\right)_{2}\right\}_{6}\left(\mathrm{C} \equiv \mathrm{CC}_{6} \mathrm{H}_{4} \mathrm{OCH}_{3}\right)_{3}\right]\left(\mathbf{3}_{\mathrm{H}}\right)\right)$ and $\mathrm{m} / \mathrm{z}$ (Cal. 2436.42) 2436.41 for $\left.\left[\mathrm{Cu}_{11}(\mathrm{D})_{2}\left\{\mathrm{~S}_{2} \mathrm{P}\left(\mathrm{O}^{i} \mathrm{Pr}\right)_{2}\right\}_{6}\left(\mathrm{C} \equiv \mathrm{CC}_{6} \mathrm{H}_{4} \mathrm{OCH}_{3}\right)_{3}\right]+\mathrm{Cu}^{+}\right]^{+} .{ }^{1} \mathrm{H} \mathrm{NMR}$ (300 MHz, $\mathrm{CDCl}_{3}$ ): 6.70 7.26 (m, $15 \mathrm{H},-\mathrm{C}_{9} \mathrm{H}_{7} \mathrm{O}$ ), 5.03 4.80 (m, $12 \mathrm{H}, \mathrm{CH}$ ), 4.65 (bs, $2 \mathrm{H}, \mu_{4}-\mathrm{H}$ ), 3.78 (s, 3H- $\mathrm{CH}_{3} \mathrm{C}_{8} \mathrm{H}_{4} \mathrm{O}$ ) $1.21 \sim 1.88$ (d, $72 \mathrm{H}, \mathrm{CH}_{3}$ ) ppm; ${ }^{13} \mathrm{C}$ NMR (400 MHz, d-Acetone): 159.63, 133.42, 116.36, 113.68, 81.57, 74.29, 74.07, 72.92, 54.79, 23.31 ppm; ${ }^{31} \mathrm{P}$ NMR (121.49 $\left.\mathrm{MHz}, \mathrm{CDCl}_{3}\right)$ : 104.0. $\left(\mathbf{3}_{\mathrm{H}}\right)$. FT-IR data in $\mathrm{KBr}$ pellet $\left(\mathrm{cm}^{-1}\right)$ : 3068.4; 2974.6; 2931.2; 2872.1; 
2000.9; 1601.7; 1503.9; 1259.9; 1177.1; 1025.1; 829.9; 756.7; 637.1; 532.1; 488.2. Elem.Anal: (Cal. C\% 31.87; H\% 4.54). Found: C\% 31.82; H\% 4.54. The presentage yield is $20.4 \%$ based on $\mathrm{Cu}$.

(3): ESI-MS: $\mathbf{m} / \mathbf{z}$ (Cal.2373.49) 2375.49 for $\left[\mathrm{Cu}_{11}(\mathrm{D})_{2}\left\{\mathrm{~S}_{2} \mathrm{P}\left(\mathrm{O}^{i} \mathrm{Pr}\right)_{2}\right\}_{6}\left(\mathrm{C} \equiv \mathrm{CC}_{6} \mathrm{H}_{4} \mathrm{OCH}_{3}\right)_{3}\right]\left(\mathbf{3}_{\mathbf{D}}\right)$ and $\mathrm{m} / \mathrm{z}$ (Cal. 2436.42) 2438.42 for $\left.\left[\mathrm{Cu}_{11}(\mathrm{D})_{2}\left\{\mathrm{~S}_{2} \mathrm{P}\left(\mathrm{O}^{i} \mathrm{Pr}\right)_{2}\right\}_{6}\left(\mathrm{C} \equiv \mathrm{CC}_{6} \mathrm{H}_{4} \mathrm{OCH}_{3}\right)_{3}\right]+\mathrm{Cu}^{+}\right]^{+}$. ${ }^{1} \mathrm{H}$ NMR (300 MHz, $\left.\mathrm{CDCl}_{3}\right):{ }^{1} \mathrm{H}$ NMR (300 MHz, $\left.\mathrm{CDCl}_{3}\right):\left(\mathrm{m}, 15 \mathrm{H},-\mathrm{C}_{9} \mathrm{H}_{7} \mathrm{O}\right.$ ), (m, $12 \mathrm{H}, \mathrm{CH}$ ), (bs, $2 \mathrm{H}$, $\mu_{4}-\mathrm{H}$ ), (s, 3H- $\mathrm{CH}_{3} \mathrm{C}_{8} \mathrm{H}_{4} \mathrm{O}$ ) (d, $72 \mathrm{H}, \mathrm{CH}_{3}$ ) ppm ppm. ${ }^{2} \mathrm{H}$ NMR (46.1 MHz, $\mathrm{CDCl}_{3}$ ): (bs, 2D, $\mu_{4}{ }^{-}$ D). ${ }^{31} \mathrm{P}$ NMR (121.49 MHz, $\left.\mathrm{CDCl}_{3}\right)$ : 104.0. (3) $\mathbf{3}_{\mathrm{D}}$. FT-IR data in $\mathrm{KBr}$ pellet $\left(\mathrm{cm}^{-1}\right)$ : 3033.9; 2974.7; 2931.2; 2871.8; 2001.9, 1601.6; 1503.9; 1251.9; 1169.8; 1026.4; 820.1; 748.3; 636.2; 531.2; 457.7. The precentage yield: $19.7 \%$ based on $\mathrm{Cu}$.

\section{Single Crystal X-ray Crystallography}

Single crystals suitable for X-ray diffraction analysis of 1, 2 and $\mathbf{3}$ were obtained by slowly diffusing hexane into a concentrated acetone solution at $-5{ }^{\circ} \mathrm{C}$ temperature. During the crystallization of $\mathbf{1}$ in acetone solution, the cocrystal of $\mathbf{1}$ and $\left[\mathrm{Cu}_{7} \mathrm{H}\right]$ also grow at the same time. The single crystals were mounted on the tip of glass fiber coated in paratone oil, then frozen at 150 K. Data were collected on a Bruker APEX II CCD diffractometer using graphite monochromated Mo Ka radiation $(\lambda=0.71073 \AA$ ). Absorption corrections for area detector were performed with SADABS ${ }^{17}$ and the integration of raw data frame was performed with SAINT ${ }^{18}$. The structure was solved by direct methods and refined by least-squares against $F^{2}$ using the SHELXL-2018/3 package, ${ }^{19-20}$ incorporated in SHELXTL/PC V6.14. ${ }^{21}$ All non-hydrogen atoms were refined anisotropically. Hydride atoms were located from the residual electron densities and refined without any constraints. In structure of $\mathbf{1}$, carbon atoms on O10, O12, and phenyl ring on C54 were disordered and split into two positions with 50\% occupancy at each. The solvent molecules were severe disordered. SQUEEZE ${ }^{22}$ program is applied to remove the peaks of unmodelled solvent molecules. In structure of 2, three $\left[\mathrm{Cu}_{11}(\mathrm{H})_{2}\left\{\mathrm{~S}_{2} \mathrm{P}\left(\mathrm{O}^{i} \mathrm{Pr}\right)_{2}\right\}_{6}\left(\mathrm{C} \equiv \mathrm{CC}_{6} \mathrm{H}_{4} \mathrm{~F}\right)_{3}\right]$ molecules were solved in asymmetric unit. One of three $\mathrm{Cu}_{11}$ clusters has minor contribution of $\left[\mathrm{Cu}_{11}(\mathrm{~S})\left\{\mathrm{S}_{2} \mathrm{P}\left(\mathrm{O}^{i} \mathrm{Pr}\right)_{2}\right\}_{6}\left(\mathrm{C} \equiv \mathrm{CC}_{6} \mathrm{H}_{4} \mathrm{~F}\right)_{3}\right]$. The occupancy ratio of $\mathrm{S}^{2-}$ and two $\mathrm{H}^{-}$is $20: 80$. The other two $\mathrm{Cu}_{11}$ molecules in asymmetric unit did not reveal heavy electron densities in the center of $\mathrm{Cu}_{11}$ framework. One phenyl ring on $\mathrm{C} 98$ was found to be disordered, and split into three 
positions. The structure reported herein has been deposited at the Cambridge Crystallographic Data Centre, CCDC 1961353 (1), CCDC 1961354 (2), and CCDC 1961355 (3).

\section{Single Crystal Neutron Diffraction}

The location of hydrides in $\mathbf{1}_{\mathbf{N}}$ was confirmed by single crystal neutron diffraction experiment using the TOPAZ single-crystal neutron time-of-flight (TOF) Laue diffractometer at ORNL's Spallation Neutron Source. ${ }^{23}$ A light yellow plate-shaped crystal $(1.75 \times 1.24 \times 0.8 \mathrm{~mm})$ was attached to a MiTeGen loop using a perfluorinated grease (Krytox GPL 205) and cooled to $100 \mathrm{~K}$ for data collection. A total of 20 crystal orientations optimized with CrystalPlan software $^{24}$ were used to ensure better than $98 \%$ coverage of a hemisphere of reciprocal space. Each orientation was measured for approximately 4 hrs. Raw peaks intensities were obtained using the 3-D ellipsoidal Q-space integration method available in Mantid. ${ }^{23}$ Data normalization including Lorentz, neutron 6 TOF spectrum, and detector efficiency corrections were carried out with the ANVRED3 program. ${ }^{25}$ A Gaussian numerical absorption correction was applied with $\mu$ $=1.1587+0.8921 \lambda \mathrm{cm}^{-1}$. The reduced data were saved in SHELX HKLF2 format in which the neutron wavelength for each reflection was recorded separately. Non-hydrogen atom positions in the X-ray structure were used for initial refinement of the neutron structure. Hydrogen atoms on carbon atoms are placed using the riding model available in SHELXL-2014 ${ }^{26}$ with the default C$\mathrm{H}$ distances for neutrons; only their displacement parameters are refined. The hydride in the asymmetric unit of $\mathbf{1}_{\mathbf{N}}$ was located from the difference Fourier map calculated using the neutron data. Hydrogen is a negative scatter for neutrons. The deepest and the second deepest hole of 3.36 and $-2.64 \mathrm{fm} \AA^{-3}$ located $~ 1.68 \AA$ from the $\mathrm{Cu} 5$ and $\mathrm{Cu} 3$ atom, respectively, were assigned as the two hydride atoms in $\mathrm{Cu}_{11}$ cluster. The third deepest hole of $-2.17 \mathrm{fm} \AA^{-3}$ located $\sim 1.57 \AA$ from $\mathrm{Cu} 12$ was assigned as the hydride atom in $\mathrm{Cu}_{7}$ cluster. The neutron structure was then refined successfully to convergence using the SHELXL-2014 program. Crystal data and selected distances are listed in Tables 1-2. The structure reported herein has been deposited at the Cambridge Crystallographic Data Centre, CCDC $\left.1967640\left(2\left[\mathbf{1}_{\mathbf{N}}\right]\left[\mathbf{4}_{\mathbf{N}}\right] .2\left[\left(\mathrm{CH}_{3}\right)_{2} \mathrm{CO}\right)\right]\right)$. 


\section{Computational details}

Geometry optimizations were performed by DFT calculations with the Gaussian 16 package, ${ }^{27}$ using the PBE0 functional, ${ }^{28}$ together with Grimme's empirical DFT-D3 corrections ${ }^{29}$ and the all-electron Def2-TZVP set from EMSL Basis Set Exchange Library. ${ }^{30}$ All the optimized geometries were characterized as true minima on their potential energy surface by harmonic vibrational analysis. The Wiberg bond indices were computed with the NBO 6.0 program. ${ }^{31}$ The ${ }^{1} \mathrm{H}$ NMR chemical shift were computed, according to the GIAO method, ${ }^{32}$ as implemented in Gaussian 16. The UV-visible transitions were calculated by means of TD-DFT calculations. Only singlet-singlet, i.e. spin-allowed, transitions were computed. The UV-visible spectra were simulated from the computed from TD-DFT ${ }^{33}$ transitions and their oscillator strengths by using the SWizard program, ${ }^{34}$ each transition being associated with a Gaussian function of half-height width equal to $3000 \mathrm{~cm}^{-1}$. The compositions of the molecular orbitals were calculated using the AOMix program. ${ }^{35}$

\section{ASSOCIATED CONTENT}

The Supporting Information is available free of charge on the ACS Publications website at DOI:

\section{AUTHOR INFORMATION}

Corresponding Author

* E-mail: chenwei@mail.ndhu.edu.tw. Tel: +886-3-8903607. Fax: +886-3-8903570.

Notes

The authors declare no competing financial interest.

\section{ACKNOWLEDGMENTS}

This work was supported by the Ministry of Science and Technology of Taiwan (MOST 1062113-M-259-010, 108 -2923-M-259-001), the France-Taiwan ANR-MOST 2018 program (project Nanoalloys) and the GENCI French national computer resource center (grant 
A0030807367). Single crystal neutron diffraction performed on TOPAZ used resources at the Spallation Neutron Source, a DOE Office of Science User Facility operated by the Oak Ridge National Laboratory, under Contract No. DE-AC05-00OR22725 with UT-Battelle, LLC.

\section{REFERENCES}

1) (a) Shima, T.; Luo, Y.; Stewart, T.; Bau, R.; Mclntyre, G. J.; Mason, S. A.; Hou, Z. Molecular heterometallic hydride clusters composed of rare-earth and d-transition metals. Nat. Chem. 2011, 3, 814-820 (b) Dhayal, R. S.; Liao, J.-H.; Kahlal, S.; Wang, X.; Liu, Y.-C.; Chiang, M.-H.; van Zyl, W. E.; Saillard, J.-Y.; Liu, C. W.

$\left[\mathrm{Cu}_{32}(\mathrm{H})_{20}\left\{\mathrm{~S}_{2} \mathrm{P}\left(\mathrm{O}^{\mathrm{i}} \mathrm{Pr}\right)_{2}\right\}_{12}\right]$ : The Largest Number of Hydrides Recorded in A Molecular Nanocluster by Neutron Diffraction. Chem. Eur. J. 2015, 21, 8369-8374. (c) Dhayal, R. S.; Liao, J.-H.; Wang, X.; Liu, Y.-C.; Chiang, M.-H.; Kahlal, S.; Saillard, J.-Y.; Liu, C. W. Diselenophosphate-Induced Conversion of an Achiral $\left[\mathrm{Cu}_{20} \mathrm{H}_{11}\left\{\mathrm{~S}_{2} \mathrm{P}\left(\mathrm{O}^{\mathrm{i}} \mathrm{Pr}\right)_{2}\right\}_{9}\right]$ into a Chiral $\left[\mathrm{Cu}_{20} \mathrm{H}_{11}\left\{\mathrm{Se}_{2} \mathrm{P}\left(\mathrm{O}^{\mathrm{i}} \mathrm{Pr}\right)_{2}\right\}_{9}\right]$ Polyhydrido Nanocluster. Angew. Chem. Int. Ed. 2015, 54, 13604-13608. (d) Edwards, A. J.; Dhayal, R. S.; Liao, P.-K.; Liao, J.-H.; Chiang, M.H.; Piltz, R. O.; Kahlal, S.; Saillard, J.-Y.; Liu, C. W. Chinese puzzle molecule; a 15 hydride, 28 copper atom nanoball. Angew. Chem. Int. Ed. 2014, 53, 7214-7218. (e) Dhayal, R. S.; Liao, J.-H.; Lin, Y.-R.; Liao, P.-K.; Kahlal, S.; Saillard, J.-Y.; Liu, C. W. A nanospheric polyhydrido copper cluster of elongated triangular orthobicupola array; liberation of $\mathrm{H}_{2}$ from solar energy. J. Am. Chem. Soc. 2013, 135, 4704-4707. (f) Liao, J.H.; Dhayal, R. S.; Wang, X.; Kahlal, S.; Saillard, J.-Y.; Liu, C. W. Neutron diffraction studies of a four-coordinated hydride in near square-planar geometry. Inorg. Chem. 2014, 53, 11140-11145.

2) (a) Haiduc, I. Inverse coordination - An emerging new chemical concept. Oxygen and other chalcogens as coordination centers. Coord. Chem. Rev. 2017, 338, 1-26, and references cited there in. (b) Haiduc, I. Inverse coordination - An emerging new chemical concept. II. Halogens as coordination centers. Coord. Chem. Rev. 2017. 348. 71-91, and references cited there in.

3) (a) Liu, C. W.; Stubbs, R. T.; Staples, R. J.; Fackler J. P., Jr. Syntheses and Structural Characterization of Two New Cu-S Cluster of Dialkyl Dithiophosphate: A SulfideCentered $\mathrm{Cu}_{8}^{\mathrm{I}}$ Cube, $\left\{\mathrm{Cu}_{8}\left[\mathrm{~S}_{2} \mathrm{P}\left(\mathrm{O}^{\mathrm{i}} \mathrm{Pr}\right)_{2}\right]_{6}\left(\mu_{8}-\mathrm{S}\right)\right\}$, and a Distorted Octahedral 
$\left\{\mathrm{Cu}_{6}\left[\mathrm{~S}_{2} \mathrm{P}(\mathrm{OEt})_{2}\right]_{6} \cdot 2 \mathrm{H}_{2} \mathrm{O}\right\}$ Cluster. J. Am. Chem. Soc. 1995, 117, 9778-9779. (b) Fackler, J. P., Jr.; Staples, R. J.; Liu, C. W.; Stubbs, R. T.; Lopez, C.; Pitts, J. T. Octahederal, Cubal and centered Cubal Dithiolate Clusters and Cages of $\mathrm{Cu}(\mathrm{I})$ and Ag(I). Pure Appl. Chem. 1998, 70, 839-844. (c) Fackler, J. P., Jr. Forty-Five Years of Chemical Discovery Including a Golden Quarter-Century. Inorg. Chem. 2002, 41, 6959-6972. (d) Huang, Z.X.; Lu, S.-F.; Huang, J.-Q.; Wu, D.-M.; Huang, J.-L.Synthesis and structure of $\mathrm{Cu}_{8} \mathrm{~S}\left[\mathrm{~S}_{2} \mathrm{P}\left(\mathrm{OC}_{2} \mathrm{H}_{5}\right)_{2}\right]_{6}$. J. Struct. Chem. 1991, 10, 213-217. (e) Wu, D.-M.; Huang, J.-Q.; Lin, Y.; Haung, J.-L. Study on the reaction performance of cluster compound- a reaction of copper(+2) capturing ligands from molybdenum cluster and the crystal structure of its product $\mathrm{Cu}_{8} \mathrm{Cl}\left[\mathrm{S}_{2} \mathrm{P}(\mathrm{OEt})_{2}\right]_{6}$. Sci. Sin. Ser. B (Engl. Ed.) 1988, 31, 800-806. (f) Matsumoto, K.; Tanaka, R.; Shimomura, R.; Nakao, Y. Synthesis and X-ray structures of octanuclear silver(I) cluster $\left[\mathrm{Ag}_{8}\left(\mu_{6}-\mathrm{S}\right)\left\{\mathrm{S}_{2} \mathrm{P}\left(\mathrm{OC}_{2} \mathrm{H}_{5}\right)_{2}\right\}_{6}\right]$ and its copper(I) analogue $\left[\mathrm{Cu}_{8}\left(\mu_{8^{-}}\right.\right.$ S) $\left.\left\{\mathrm{S}_{2} \mathrm{P}\left(\mathrm{OC}_{2} \mathrm{H}_{5}\right)_{2}\right\}_{6}\right]$. Inorg. Chim. Acta 2000, 304, 293-296. (g) Latouche, C.; Liu, C.-W.; Saillard, J.-Y. Encapsulating hydrides and main-group anions in d10-metal clusters stabilized by 1,1-dichacogeno ligands. J. Clust. Sci. 25, 2014, 25, 147-171.

4) Liu, C. W.; Chen, H.-C.; Wang, J.-C.; Keng, T.-C. First selenide-centered $\mathrm{Cu}_{8}$ cubic cluster containing dialkyldiselenophosphate ligands. X-ray structures $\mathrm{Cu}_{8}\left(\mu_{8}\right.$-Se) $\left[\mathrm{Se}_{2} \mathrm{P}\left(\mathrm{O}^{i} \mathrm{Pr}\right)_{2}\right]$. Chem. Commun. 1998, 1831-1832.

5) Liu, C. W.; Shang, I.-J.; Wang, J.-C.; Keng, T.-J. Metal dialkyl diselenphosphate; a rare example of co-crystallization with cluters, $\mathrm{Ag}_{8}\left(\mu_{8}-\mathrm{Se}\right)\left[\mathrm{Se}{ }_{2} \mathrm{P}\left(\mathrm{O}^{i} \mathrm{Pr}\right)_{2}\right]_{6}$ and $\mathrm{Ag}_{6}\left[\mathrm{Se}_{2} \mathrm{P}\left(\mathrm{O}^{i} \mathrm{Pr}\right)_{2}\right]_{6}$ Chem. Commun. 1999, 995-996.

6) (a) Liu, C. W.; Hung, C.-M.; Santra, B. K.; Chen, H.-C.; Hsueh, H.- H.; Wang, J.-C. Novel chloride-centered discrete $\mathrm{Cu}_{8}^{\mathrm{I}}$ cubic cluster containing diselenophosphate ligands. Syntheses and structures of $\mathrm{Cu}_{8}\left(\mu_{8}-\mathrm{Cl}\right)\left[\mathrm{Se}_{2} \mathrm{P}(\mathrm{OR})_{2}\right]_{6} \mathrm{PF}_{6}\left(\mathrm{R}=\mathrm{Et}\right.$, $\left.\mathrm{Pr},{ }^{\mathrm{i}} \mathrm{Pr}\right)$. Inorg. Chem. 2003, 42, 3216-3220.; (b) Liu, C. W.; Hung, C.-M.; Chen, H.-C.; Wang, J.-C.; Keng, T.C.; Guo, K.-M. A novel nanocoordinate bridging selenido ligand in a tricapped trigonal prismatic geometry. X-ray structure of $\mathrm{Cu}_{11}\left(\mu_{9}-\mathrm{Se}\right)\left(\mu_{3}-\mathrm{Br}\right)\left[\mathrm{Se}_{2} \mathrm{P}\left(\mathrm{O}^{i} \mathrm{Pr}\right)_{2}\right]_{6}$. Chem. Commun. 2000, 1897-1998.

7) (a) Liu, C. W.; Haia, H.-C.; Hung, C.-M.; Santra, B. K.; Liaw, B.-J.; Wang, J.-C.; Lin, Z. New halide-centered discrete $\mathrm{Ag}_{8}^{\mathrm{I}}$ cubic cluster containing diselenphosphate ligands, $\mathrm{Cu}_{8}\left(\mu_{8}-\mathrm{X}\right)\left[\mathrm{Se}_{2} \mathrm{P}(\mathrm{OR})_{2}\right]_{6} \mathrm{PF}_{6}\left(\mathrm{X}=\mathrm{Cl}, \mathrm{Br} ; \mathrm{R}=\mathrm{Et}, \mathrm{Pr},{ }^{\mathrm{i}} \mathrm{Pr}\right)$. Inorg. Chem. 2004, 43, 4464- 
4470.; (b) Liu, C. W.; Hung, C.-M.; Haia, H.-C.; Liaw, B.-J.; Liou, L.-S.; Tsai, Y.-F.; Wang, J.-C. $\mathrm{Ag}_{8} \mathrm{Cl}_{2}\left[\mathrm{Se}_{2} \mathrm{P}(\mathrm{OEt})_{2}\right]_{6}$ : A Rare Example Containing a Combination of Discrete Clusters and Chains. Chem. Commun. 2003, 976-977.

8) (a) Liu, C. W.; Hung, C.-M.; Wang, J.-C.; Keng, T.-C. Characterizations of $\mathrm{Cu}_{11}\left(\mu_{9}-\mathrm{Se}\right)$ $\left(\mu_{3}-\mathrm{I}\right)\left[\mathrm{Se}_{2} \mathrm{P}(\mathrm{OR})_{2}\right]_{6}(\mathrm{R}=\mathrm{iPr}, \mathrm{Pr})$ by X-ray diffraction and multinuclear NMR. J. Chem. Soc., Dalton Trans. 2002, 3482-3488. (b) Liu, C. W.; Hung, C.-M.; Santra, B. K.; Chu, Y.-H.; Wang, J.-C.; Lin, Z. A Nanocoordinated Bridging Selenide in a Tricapped Trigonal Prismatic Geometry Identified Copper Cluster in Undecanuclear Cluster. Syntheses, Structures and DFT calculation. Inorg. Chem. 2004, 43, 4306-4316. (c) Hung, C.-M.; Chu, Y.-H.; Santra, B. K.; Liaw, B.-J.; Wang, J.-C.; Liu, C. W. J. Intermolecular Se Interactions Identified in $\mathrm{Cu}_{11}\left(\mu_{9}-\mathrm{Se}\right)\left(\mu_{3}-\mathrm{I}\right)\left[\mathrm{Se}_{2} \mathrm{P}(\mathrm{OEt})_{2}\right]_{6}$ form a one dimensional polymeric chain. J. Chin. Chem. Soc. 2006, 53, 825-830.

9) (a) Liu, C. W.; Feng, C.-S.; Fu, R.-J.; Chang, H.-W.; Saillard, J.-Y.; Kahlal, S.; Wang, J.C.; Chang, I.-J. Structure, Photophysical Properties, and DFT Calculations of SelenideCentered Pentacapped Trigonal Prismatic Silver(I) cluster. Inorg. Chem. 2010, 49, 49344941. (b) Liu, C. W.; Shang, I. J.; Fu, R.-J.; Liaw, B.-J.; Wang, J.-C.; Chang, I.-J. Selenium-Centered Undecanuclear Silver Cages Surrounded by Iodo and Dialkyl Diselenophosphato Ligands; Syntheses, Structures, and Photophysical Properties. Inorg. Chem. 2006, 45, 2335-2340.

10) Li, Y-J; Latouche, C; Kahlal, S; Liao, J-H; Dhayal, R. S; Sailard, J.-Y; Liu, C.W. A $\mu_{9-}$ Iodide in a Tricapped Trigonal-Prismatic Geometry. Inorg. Chem. 2012, 51, 7439-7441.

11) Li, B.; Liao, J.-H.; Tang, H.-T.; Li, Y.-J.; Liu, C. W. Substitution reactions on a hypercoordinated main-group element encapsulated in a pentacapped trigonal prismatic copper cage. Dalton Trans. 2013, 42, 14384-14387.

12) Chakrahari, K. K.; Liao, J.-H.; Kahlal, S.; Liu, Y.-C.; Chiang, M.-H.; Saillard, J.-Y.; Liu, C. W. $\left.\left[\mathrm{Cu}_{13}\left(\mathrm{~S}_{2} \mathrm{CN}^{\mathrm{n}} \mathrm{Bu}\right)_{6} \text { (acetylide) }\right)_{4}\right]^{+}$:A Two-Electron Superatom. Angew. Chem. Int. Ed. 2016, 55, 14.

13) Liao, P.-K.; Fang, C.-S.; Edwards, A. J.; Kahlal, S.; Saillard, J.-Y.; Liu, C. W. Hydrido copper cluster supported by dithiocarbamates: oxidative hydride removal and neutron diffraction analysis of $\left[\mathrm{Cu}_{7}(\mathrm{H})\left\{\mathrm{S}_{2} \mathrm{C}(\text { aza-15-crown-5) }\}_{\mathrm{S}}\right]\right.$. Inorg. Chem. 2012, 51, 65776591. 
14) a) Dhayal, R. S.; van Zyl, W. E.; Liu, C. W. Polyhydrido Copper Clusters: Synthesis Advances, Structural Diversity, and Nanocluster-to-Nanoparticle Conversion. Acc. Chem. Res. 2016, 49, 86-95. b) Dhayal, R. S.; van Zyl, W. E.; Liu, C. W. Copper hydride clusters in energy storage and conversion. Dalton Trans. 2019, 48, 3531-3548. c) Sun, C.; Mammen, N.; Kaappa, S.; Yuan, P.; Deng, G.; Zhao, C.; Yan, J.; Malola, S.; Honkala., K.; Häkkinen, H.; Teo, B. K.; Zheng, N. Atomically Precise, Thiolated Copper-Hydride Nanocluster as Single-Site Hydrogenation Catalysis for Ketones in Mild Conditions. ACS Nano., 2019, 13, 5975-5986. d) Nguyen, T. A. D.; Jones, Z. R.; Goldsmith, B. R.; Buratto, W. R.; Wu, G.; Scott, S. L.; Hayton, T. W. A $\mathrm{Cu}_{25}$ Nanocluster with Partial $\mathrm{Cu}(0)$ Character. J. Am. Chem. Soc., 2015, 134, 13319-13324. e) Huertos, M. A.; Cano, I.; Bandeira, N. A. G.;Benet-Buchholz, J.; Bo, C.; van Leeuwe, P. W. N. M. Phosphinothiolates as Ligands for Polyhydrido Copper Nanocluster. Chem. Eur. J., 2014, 20, 16121-16127. f) Li, J.; Ma, H. Z.; Reid, G. E.; Edwards, A. J.; Hong, Y.; White, J. M.; Mulder, R. J.; O’Hair, R. A. J. Synthesis and X-Ray crystallographic Characterization of Frustum-Shaped Ligated $\left[\mathrm{Cu}_{18} \mathrm{H}_{16}(\mathrm{DPPE})_{6}\right]^{2+}$ and $\left[\mathrm{Cu}_{16} \mathrm{H}_{14}(\mathrm{DPPA})_{6}\right]^{2+}$ Nanoclusters and Studies on Their $\mathrm{H}_{2}$ Evolution Reactions. Chem. Eur. J. 2018, 24, 2070-2074. g) Nakamae, K.; Nakaima, T.; Ura, Y.; Kitagawa, Y.; Tanase, T. Facially Dispersed Polyhdride $\mathrm{Cu}_{9}$ and $\mathrm{Cu}_{19}$ Clusters Comprising Apex-Truncated Supertetahedral and Square-face-Capped Cuboctahedral Copper Frameworks. Angew. Chem. Int. Ed., 2019, DOI: 10.1021/anie.201913533. h) Ghosh, A.; Huang, R.-W.; Alamer, B.; Abou-Hamad, E.; Hedhili, M. N.; Mohammed, O. F.; Bakr, O. M. [ $\left.\mathrm{Cu}_{61}\left(\mathrm{~S}^{t} \mathrm{Bu}\right)_{26} \mathrm{~S}_{6} \mathrm{C}_{16} \mathrm{H}_{14}\right]^{+}$: A CoreShell Superatom Nanocluster with a Quasi- $J_{36} \mathrm{Cu}_{19}$ Core and an "18-Crown-6" MetalSulfide-like Stabilizing Belt. ACS Materials Lett., 2019, 1, 297-302. i) Yuan, P.; Chen, R.; Zhang, X.; Chen, F.; Yan, J.; Sun, C.; Ou, D.; Peng, J.; Lin, S.; Tang, Z.; Teo, B. K.; Zheng, L.-S.; Zheng, N. Ether-Soluble $\mathrm{Cu}_{53}$ Nanocluster as an Effective Precursor of High-Quality CuI Films for Optoelectronic Applications. Angew. Chem. Int. Ed., 2018, 58, 835-839. j) Chen, A.: Kang, X.; Jin, S.; Du, W.; Wang, S.; Zhu, M. Gram-Scale Preparation of Stable Hydride $\mathrm{M} @ \mathrm{Cu}_{24}(\mathrm{M}=\mathrm{Au} / \mathrm{Cu})$ Nanoclusters. J. Phys. Chem. Lett., 2019, 10, 6124-6128.

15) Kubas, G. J; Monzyk, B.; Crumbliss, A. L. Tetrakis(Acetonitrile)Copper(I) Hexfluorophosphate. Inorg. Synth. 1979, 19, 90-92. 
16) Wystrach, P.; Hook, E. O.; Christopher, G. L. M. Notes - Basic Zinc Double Salt of O, O-Diakyl Phosphorodithio Acid. J. Org. Chem. 1956, 21, 705-707.

17) SADABS, version 2014-11.0, Bruker Area Detector Absorption Corrextions (Bruker AXS Inc., Madison, WI, 2014).

18) SAINT, included in G. Jogl, V4.043: Software for the CCD detector system (Bruker Analytical: Madison, WI, 1995).

19) Sheldrick, G. M. Acta Cryst. A 2008, 64, 112-122.

20) Gruene, T.; Hahn, H. W.; Luebben, A. V.; Meilleur, F.; Sheldrick, G. M. J. Appl. Cryst. 2014, 47, 462-466.

21) SHELXTL, version 6.14. (Bruker AXS Inc., Madison, Wisconsin, USA, 2003).

22) PLATON/SQUEEZE Spek, A. L. Acta Cryst. 2009, D65, 148-155.

23) Schultz, A. J.; Jorgensen, M. R. V.; Wang, X.; Mikkelson, R. L.; Mikkelson, D. J.; Lynch, V. E.; Peterson, P. F.; Green, M. L.; Hoffmann, C. M. J. Appl. Cryst. 2014, 47, 915-921.

24) Zikovsky, J.; Peterson, P. F.; Wang, X. P.; Frost, M.; Hoffmann, C. J. Appl. Cryst. 2011, 44, 418-423.

25) Schultz, A. J.; Srinivasan, K.; Teller, R. G.; Williams, J. M.; Lukehart, C. M. J. Am. Chem. Soc. 1984, 106, 999-1003.

26) Sheldrick, G. M. ActaCryst. 2015, C71, 3-8.

27) Gaussian 16, Revision C.01, Frisch, M. J.; Trucks, G. W.; Schlegel, H. B.; Scuseria, G. E.; Robb, M. A.; Cheeseman, J. R.; Scalmani, G.; Barone, V.; Petersson, G. A.; Nakatsuji, H.; Li, X.; Caricato, M.; Marenich, A. V.; Bloino, J.; Janesko, B. G.; Gomperts, R.; Mennucci, B.; Hratchian, H. P.; Ortiz, J. V.; Izmaylov, A. F.; Sonnenberg, J. L.; Williams-Young, D.; Ding, F.; Lipparini, F.; Egidi, F.; Goings, J.; Peng, B.; Petrone, A.; Henderson, T.; Ranasinghe, D.; Zakrzewski, V. G.; Gao, J.; Rega, N.; Zheng, G.; Liang, W.; Hada, M.; Ehara, M.; Toyota, K.; Fukuda, R.; Hasegawa, J.; Ishida, M.; Nakajima, T.; Honda, Y.; Kitao, O.; Nakai, H.; Vreven, T.; Throssell, K.; Montgomery, J. A., Jr.; Peralta, J. E.; Ogliaro, F.; Bearpark, M. J.; Heyd, J. J.; Brothers, E. N.; Kudin, K. N.; Staroverov, V. N.; Keith, T. A.; Kobayashi, R.; Normand, J.; Raghavachari, K.; Rendell, A. P.; Burant, J. C.; Iyengar, S. S.; Tomasi, J.; Cossi, M.; Millam, J. M.; Klene, M.; Adamo, C.; Cammi, R.; Ochterski, J. W.; Martin, R. L.; Morokuma, K.; Farkas, O.; Foresman, J. B.; Fox, D. J. Gaussian, Inc., Wallingford CT, 
2016.

28) C. Adamo, A.; Barone, V. Toward reliable density functional methods without adjustable parameters: The PBE0 model. J. Chem. Phys. 1999, 110, 6158-69.

29) Grimme, S.; Ehrlich, S.; Goerigk, L. Effect of the damping function in dispersion corrected density functional theory. J. Comp. Chem. 2011, 32, 1456-65.

30) F. Weigend, F.; Ahlrichs, R. Balanced basis sets of split valence, triple zeta valence and quadruple zeta valence quality for $\mathrm{H}$ to $\mathrm{Rn}$ : Design and assessment of accuracy. Phys. Chem. Chem. Phys. 2005, 7, 3297-305.

31) Glendening, E.D.; Badenhoop, J. K.; Reed, A. E.; Carpenter, J. E.; Bohmann, J. A.; Morales, C. M.; Landis, C. R.; Weinhold, F. NBO 6.0; Theoretical Chemistry Institute, University of Wisconsin, Madison, WI, 2013, http://nbo6.chem.wisc.edu.

32) Wolinski, K.; Hilton, J. F.; Pulay, P. Efficient Implementation of the Gauge-Independent Atomic Orbital Method for NMR Chemical Shift Calculations. J. Am. Chem. Soc. 1990, 112, 8251-60.

33) Ullrich, C. Time-Dependent Density-Functional Theory, Concepts and Applications, Oxford University Press, NewYork, 2012.

34) Gorelsky, S. I. SWizard program, revision 4.5, http://www.sg-chem.net.

35) Gorelsky, S. I. AOMix program, http://www.sg-chem.net. 
Image for Table of Contents

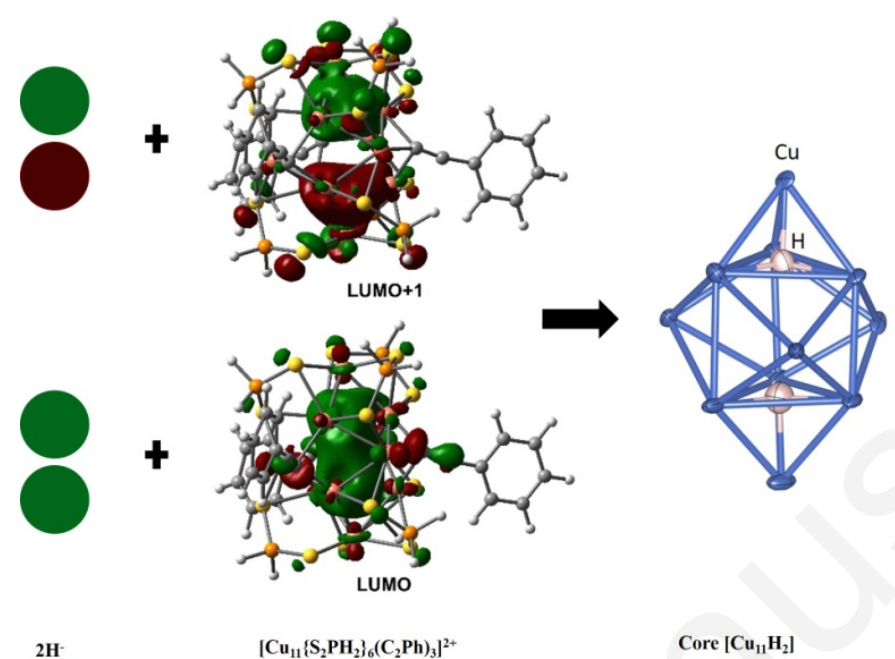

